\title{
La renegociación de Contratos de concesión en el Perú. Aproximación teórica y empírica a sus causas y consecuencias( $^{(*)}$
}

\section{The renegotiation of concession contracts in Peru. A theoretical and empirical approach to their causes and consequences}

\author{
María Teresa Quiñones Alayza ${ }^{(* *)}$ \\ Quiñones Alayza Abogados \\ Jenny Aliaga Aliaga $a^{(*+*)}$ \\ Ministerio de Cultura
}

\begin{abstract}
Resumen: El Estado peruano apostó por las Asociaciones Público Privadas (APP) como un mecanismo efectivo para cerrar la brecha en infraestructura. No obstante, las constantes modificaciones a su marco legal, los retrasos en la ejecución de los proyectos y las frecuentes adendas a los contratos de concesión, particularmente en el caso de los cofinanciados, han generado desconfianza en la sociedad y afectado la credibilidad del modelo.

El presente trabajo analiza las principales causas de renegociación de los contratos de concesión adjudicados por Prolnversión, así como los costos derivados de la renegociación excesiva. Como se verá, los beneficios que el Estado peruano obtiene por actuar oportunistamente, adjudicando proyectos que carecen de estudios suficientes y de una asignación adecuada de riesgos, se ven contrarrestados por el impacto en la legitimidad del modelo de APP y por las dilaciones en la culminación de proyectos destinados a atender necesidades públicas. Sin embargo, nuestra investigación evidencia que el Estado es proclive a priorizar los beneficios que recibe a corto plazo frente a los costos a largo plazo que conlleva la adjudicación prematura de proyectos.
\end{abstract}

Palabras clave: Asociación Público-Privada - Concesión - Renegociación - Análisis costobeneficio - Costos de la renegociación - Identificación y asignación de riesgos - Comportamiento oportunista - Perú

\begin{abstract}
The Peruvian Government decided to use Public-Private Partnerships as a tool in its infrastructure policy. However, the constant amendments to the legal framework, the delays in the execution of projects and the frequent addend to concession contracts (specifically, those which are co-financed) have created distrust in society and affected the credibility of this model.

This article analyses the main causes foref renegotiation of concession contracts awarded by Prolnversión and the derived costs of excessive renegotiation. Our data shows that the benefits that the Peruvian Government obtains by acting opportunistically: i.e., by awarding projects that lack sufficient studies or an adequate risk assignment, are countered by the impact on the legitimacy of Public-Private Partnerships and by the delays in the completion of projects destined to attend public needs. However, our research shows that the Government is prone to prioritize the benefits it receives in the short term disregarding the long term costs that a premature awarding of projects entails.
\end{abstract}

Keywords: Public-Private Partnership - Concession - Renegotiation - Cost-Benefit Analysis Renegotiation costs - Identification and assignation of risks - Opportunistic behavior - Peru

(*) Nota del Editor: el artículo fue recibido el 8 de marzo de 2019 y su publicación fue aprobada el 2 mayo de 2019.

$\left({ }^{* *}\right)$ Abogada por la Pontificia Universidad Católica del Perú. Directora de la Maestría de Derecho Administrativo Económico de la Universidad del Pacífico. LL.M. Harvard University. Socia de Quiñones Alayza Abogados. Correo electrónico: mqa@qabogados.pe

${ }^{(* * *}$ Egresada de la Facultad de Derecho de la Pontificia Universidad Católica del Perú. Especialista legal para la Dirección de Consulta Previa del Ministerio de Cultura. Correo electrónico: aliaga.jenny@gmail.com 


\section{Introducción}

Las Asociaciones Público-Privadas (en adelante, "APP") han sido un mecanismo eficaz para promover la colaboración del sector privado en la dotación de obras y servicios públicos indispensables. Su relevancia en el Perú es tal que, entre los años 1998 y 2017, se han adjudicado 95 proyectos APP de iniciativa estatal, con una inversión proyectada de más de 29 mil millones de dólares (Prolnversión 2017). La necesidad de emplear APP se justifica por la magnitud de la brecha en infraestructura, calculada por Bonifaz y otros. (2015) para el periodo 2016-2025, en USD 160,000 millones, equivalente al $80 \%$ del PBI peruano.

No obstante, la frecuente renegociación de los contratos de concesión de obra pública -que es la técnica contractual más utilizada para APP de gran envergadura-, particularmente en el caso de concesiones cofinanciadas, ha sido un elemento que ha generado desconfianza en la sociedad y afectado la credibilidad del modelo(1).

Un indicio de las marchas, contramarchas y cuestionamientos que han existido en relación con la promoción de la inversión privada a través de APP ha sido la frecuencia con la que se ha modificado el marco legal que las regula. El vigente Decreto Legislativo 1362 ("Ley de APP") entró en vigor el pasado 31 de octubre de 2018, con la publicación del Decreto Supremo 240-2018-EF ("Reglamento de la Ley de APP").

En el presente trabajo analizamos las principales causas de adendas a los contratos de concesión de obra pública y los costos derivados de su renegociación excesiva. Asimismo, deseamos compartir los hallazgos obtenidos al investigar las modificaciones a los contratos adjudicados por Prolnversión ${ }^{(2)}$ en el periodo 1998-2017.

Nuestra intención es aportar al conocimiento de los elementos que dan origen a estas renegociaciones, así como de sus consecuencias, tanto desde una aproximación teórica como empírica. Estamos convencidas de que sólo integrando ambas perspectivas será posible diseñar mejores APP en un entorno institucional que ofrezca los incentivos correctos para promover la construcción y gestión de infraestructura esencial, reduciendo el riesgo de renegociaciones que son consecuencia de conductas oportunistas, tanto del Estado como de los particulares.

\section{La técnica concesional en el marco de las APP}

Si bien desde el siglo XIX muchos países tributarios del Derecho Continental recogían la figura de la concesión -originaria de Francia-como un mecanismo para conseguir recursos privados que permitiesen solventar la construcción de infraestructura y servicios públicos ${ }^{(3)}$, el gran aporte de las APP fue abrir el espectro de la distribución de riesgos y recursos entre el Estado y el privado(4).

(1) En el caso peruano, las sospechas de corrupción en concesiones vinculadas al caso "Lava Jato", así como las frecuentes renegociaciones han llevado a que algunos propongan la eliminación de las APP cofinanciadas y el retorno al régimen de contratos de obra pública para las grandes obras de infraestructura. Como ejemplo, basta ver el reciente caso de Chavimochic, donde todo parece indicar que va a reconvertirse de concesión en obra pública, con los sobrecostos e ineficiencias que conlleva la gestión y el mantenimiento estatal de esta clase de infraestructura.

(2) Cabe señalar que mediante Decreto Supremo 27-2002-PCM se dispuso la fusión de la COPRI, la Comisión Nacional de Inversiones y Tecnologías Extranjeras y la Gerencia de Promoción Económica de la Comisión de Promoción del Perú, en la Dirección Ejecutiva FOPRI, la cual pasó a denominarse Prolnversión.

(3) "El origen histórico de la institución concesional se encuentra en la obra pública (...) la falta de liquidez del Estado para afrontar la construcción de obras públicas determinó la necesidad de apelar a la colaboración del capital privado para efectuar tal labor pública (...) La razón que justifica la evolución del contrato de obra pública hacia la concesión de servicio público no es otra que la coexistencia de una necesidad pública y la impotencia económico-financiera del Estado para afrontar su ejecución (...)” (Mestre 1992, 24-25).

(4) Al respecto, es ilustrativa la reseña que hace Mestre (1992, 33-34) sobre el Informe Subercasse, documento emitido el 2 de noviembre de 1844, que analiza las modalidades teóricas que existían para desarrollar el sistema de ferrocarriles en España:

“(...) que, resumidamente, eran: 1), mediante la iniciativa privada, como, según afirmaban, ocurría en Gran Bretaña y Estados Unidos; 2), mediante la directa promoción por el Estado, como sucedía en Bélgica en la mayor parte de los casos; o 3), mediante una modalidad mixta, en la que 'el Gobierno' hacía el camino y las compañías sólo se encargaban de la explotación, la cual se adjudicaba en pública subasta, como era el caso de Francia.

De las tres soluciones, la Comisión mostró su preferencia por la modalidad de ejecución por cuenta del Estado, pero como fórmula abstracta (...) señala, en este sentido, el Informe, que 'dondequiera que el Gobierno tenga su crédito bien sentado, es preferible ejecutar las obras por cuenta del Estado', afirmación que justificaba en las circunstancias de que ese sistema era el único que permitía: 1) conseguir que los transportes de personas y mercancías se reduzcan al mínimo precio, compatible con el sostenimiento del camino después de amortizar el capital; 2) modificar las tarifas en beneficio de los productos que convenga fomentar; 3) permitir 
En efecto, a diferencia de la concesión tradicional, que trasladaba al concesionario la responsabilidad de construir y explotar la concesión "a su riesgo y ventura", en las APP es posible asignar los riesgos entre las partes de una manera bastante más flexible, atendiendo al perfil del proyecto, a criterios de economía, eficiencia y eficacia, así como a la capacidad que cada una de ellas tiene para soportarlos (Céspedes y Paz 2018, 13-14).

Un aspecto medular para entender la problemática de la renegociación en las APP -técnica que tiene su origen en el Reino Unido, cuando el gobierno de Margaret Thatcher adoptó el New Public Management como forma de gobierno y administración de las políticas públicas (Céspedes y Paz 2018, 13)- es el principio de colaboración:

“(...) según el cual la Administración no considera al contratista como un antagonista, sino como un colaborador (...) (Baca y Ortega 2013, 36), de lo cual se deriva que hay ciertos riesgos que pueden ser compartidos" (Céspedes y Paz 2018, 18-19).

Al ser colaboradores en la consecución de un proyecto común -el diseño, construcción y operación de una infraestructura pública que presta un servicio público-, será deber de ambas partes negociar e incorporar aquellas modificaciones en el contrato que permitan responder frente a escenarios imprevistos, adecuarse a cambio tecnológicos o legales y reestablecer el equilibrio económico-financiero; todo ello en aras de asegurar la continuidad y correcta prestación del servicio público, que es el fin último del interés público que está llamada a atender la APP.

Este es, justamente, el enfoque de nuestra Ley de APP, cuyo artículo 20 las define como "una modalidad de participación de la inversión privada, mediante contratos de largo plazo en los que interviene el Estado, a través de alguna entidad pública y uno o más inversionistas privados", que tiene su origen en una iniciativa estatal o privada, destinada a desarrollar "proyectos de infraestructura pública, servicios públicos, servicios vinculados a infraestructura pública y servicios públicos, investigación aplicada y/o innovación tecnológica (...)" en las que "se distribuyen riesgos y recursos, en este último caso, preferentemente privados".

Nótese que en la definición precedentemente citada se reconoce, como nota distintiva de las APP, la distribución de riesgos y recursos entre las partes; aun cuando se precisa, respecto de los recursos, que la preferencia es porque sean privados. Esta distribución de riesgos entre el Estado y el inversionista es la manera como se materializa en las APP el principio de colaboración entre agentes públicos y privados, con el fin de desarrollar infraestructura esencial.

De otro lado, la necesidad de contar con recursos privados para financiar, diseñar y gestionar infraestructura técnicamente compleja y de alto costo es la principal justificación de las APP; es decir, de admitir - muchas veces a regañadientes, como reconocía el Informe Subercasse ${ }^{(5)}$ - la participación privada en la dotación y explotación de infraestructura y servicios públicos, incluso con subsidio o cofinanciamiento estatal, debido a las restricciones presupuestarias y carencias técnicas del Estado.

Es pertinente señalar que la adopción del modelo de APP ha sido impulsada por los organismos multilaterales de crédito. Precisamente, uno de ellos, el Banco Mundial $(2014,32)$ destaca como uno de los "motores de valor de las APP" el principio de "transferencia de riesgos". En virtud de este, el Gobierno deja de asumir algunos riesgos en relación con el diseño, construcción, financiamiento, operación y mantenimiento de la infraestructura, transfiriéndolos al sector

a los usuarios entrar en el goce del servicio y de todas las mejoras, lo que no se conseguirá nunca 'a través de las compañías por su tendencia egoísta a ejercer el monopolio'; y 4) emprender con utilidad pública muchas líneas que para las compañías serían ruinosas, 'dado el distinto criterio seguido por aquéllas frente a la Administración, que desea siempre y en primer lugar el incremento de la riqueza pública y el bienestar de los gobernados'.

El 'Informe Subercasse' señalaba, no obstante ello, que ese no era el caso español de la época, y por ello hubo de renunciar, 'por evidente falta de recursos en el país', a que la Administración acometiera la financiación pública de la construcción de los ferrocarriles. En los casos -como era el español- en que la Administración de un país no quisiera o no pudiera hacer frente por sí misma a la construcción del ferrocarril, la Comisión admitía, como mal menor, el recurso a la iniciativa privada."

A la necesidad insoslayable de financiar con recursos privados infraestructura considerada esencial, cabría agregar que la concesión era consistente con la ideología liberal, pues permitía materializar el principio del Estado subsidiario, aún en el caso de los servicios públicos. Por esta razón, como se menciona en el Informe Subercasse, en Francia se utilizaba la concesión para delegar en el sector privado la gestión de infraestructura construida por el Estado.

(5) Ver nota 4 
privado. Como ya se ha señalado, dicha "transferencia" es, en realidad, una "distribución", que implica asignar cada riesgo a la parte que se encuentra en mejor posición de controlarlos o mitigarlos, e incluso soportarlos (Céspedes y Paz 2018, 19), teniendo en cuenta el perfil específico del proyecto de que se trate:

"The Government recognizes that there are some things which the private sector does best and others where the public sector has more to offer. The old argument, as to whether public ownership was always best or whether privatisation was the only answer, is simply outdated. The Government firmly believes it will only deliver the modern, high quality public services that the public want and increasingly expect if it draws on the best of both public and private sectors"(6) (citado por Ronceros 2006, 232).

El instrumento para materializar estas APP en nuestro país ha sido el contrato de concesión, que ha devenido en la técnica contractual más utilizada, a guisa de transformarse en una herramienta que garantiza tanto el equilibrio económico bidireccional como una distribución de riesgos y beneficios entre las partes (Ariño 2004, 713). Su flexibilidad y adaptabilidad permiten añadir, a sus características tradicionales (delegación por la Administración de un cometido estatal a un privado, por un plazo determinado, para la construcción y explotación de infraestructura de uso público o de un servicio público), un modelo de asignación de riesgos estructurado según el perfil del proyecto, que tome en cuenta la capacidad de las partes para soportarlos, amén de mecanismos para restablecer el equilibrio económico y para modificar la concesión en los supuestos previstos en la legislación y en el propio contrato.

\section{Algunas cifras sobre las APP adjudicadas y sus adendas}

Como se aprecia en el Cuadro No. 1, la mayoría de APP de iniciativa estatal adjudicadas se encuentra en el sector energía. En segundo lugar, está la infraestructura de transporte y, en tercer lugar, las telecomunicaciones. Les siguen los proyectos de saneamiento, agricultura, turismo y salud.

Si bien durante más de veinte años, la modalidad APP ha sido utilizada para la construcción de obras de gran envergadura, consideradas esenciales para el desarrollo del país, muchos de los proyectos adjudicados han tenido dificultades en su ejecución, lo que ha obligado a su renegociación, a fin de permitir su viabilidad.

\section{Cuadro No. 1 \\ Proyectos de iniciativa estatal adjudicados 1998-2017}

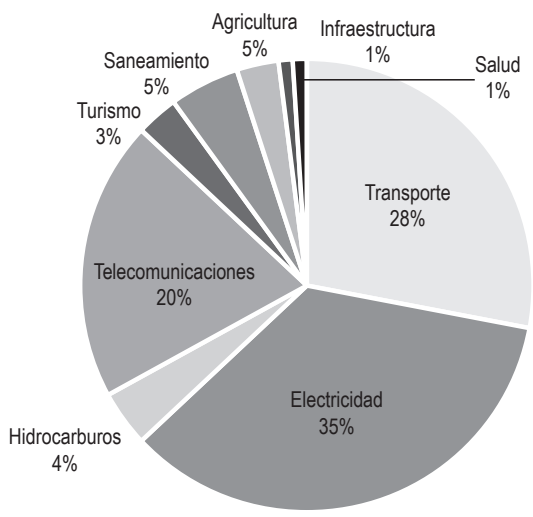

Según la Contraloría General de la República $(2015,141)$ entre los años 2000 y 2013 se celebraron 103 adendas a los contratos de concesión suscritos en el mismo periodo, lo que hace un promedio de 7 adendas por año. En su estudio, la Contraloría identificó que hasta el año 2012, 20 de los 26 contratos de concesión de obras de infraestructura de transporte (es decir, el $77 \%$ ) fueron renegociados en múltiples oportunidades, habiéndose suscrito 72 adendas.

De acuerdo con la clasificación efectuada por Cienfuegos $(2019,111)$, el período durante el cual se suscribió el mayor número de renegociaciones corresponde al gobierno de Ollanta Humala (con un total de 85 adendas), siguiendo el de Alan García, con 71. En el caso del actual gobierno, las adendas suscritas a febrero de 2019 totalizan 50 .

Benavente y Segura $(2017,46)$ constatan, asimismo, que la mayoría de los contratos de concesión de infraestructura de transporte vigentes a agosto del 2017 fueron modificados, suscribiéndose 109 adendas. En lo que respecta a los proyectos cofinanciados de ese sector, Céspedes y Paz $(2018,73)$ mencionan que 13 de los 16 contratos suscritos fueron objeto de 56 adendas.

(6) Declaración del Gobierno Británico del año 2000. Traducción libre: “El Gobierno reconoce que existen ciertas cosas que el sector privado hace mejor y otras en las que el sector público tiene más que ofrecer. La vieja discusión sobre si la propiedad estatal era siempre lo mejor o si la privatización era la única respuesta, ha quedado obsoleta. El Gobierno cree firmemente que sólo podrá ofrecer los servicios públicos modernos y de alta calidad que el público desea y demanda cada vez más, si toma lo mejor de los sectores público y privado." 
Renegociaciones de contratos de APP: Por periodo de gobierno

\begin{tabular}{|c|c|c|c|c|c|c|}
\hline $\begin{array}{l}\text { Año de } \\
\text { elección }\end{array}$ & 2000 & 2000 & 2001 & 2006 & 2011 & 2016 \\
\hline $\begin{array}{l}\text { Período de } \\
\text { gobierno }\end{array}$ & $\begin{array}{l}28 \text { de julio } \\
\text { de } 1995 \\
\text { - } 21 \text { de } \\
\text { noviembre } \\
\text { de } 2000\end{array}$ & $\begin{array}{l}22 \text { de } \\
\text { noviembre } \\
2000-28 \\
\text { de julio } \\
2001\end{array}$ & $\begin{array}{l}28 \text { de julio } \\
2001-28 \\
\text { de julio } \\
2006\end{array}$ & $\begin{array}{l}28 \text { de julio } \\
2006-28 \\
\text { de julio } \\
2011\end{array}$ & $\begin{array}{l}28 \text { de julio } \\
2011 \text { - } 28 \\
\text { de julio } \\
2016\end{array}$ & $\begin{array}{l}28 \text { de julio } \\
2016-28 \\
\text { de julio } \\
2021\end{array}$ \\
\hline Presidentes & $\begin{array}{l}\text { Alberto } \\
\text { Fujimori }\end{array}$ & $\begin{array}{l}\text { Valentín } \\
\text { Paniagua }\end{array}$ & $\begin{array}{l}\text { Alejandro } \\
\text { Toledo }\end{array}$ & $\begin{array}{l}\text { Alan } \\
\text { García }\end{array}$ & $\begin{array}{l}\text { Ollanta } \\
\text { Humala }\end{array}$ & $\begin{array}{l}\text { Pedro } \\
\text { Pablo } \\
\text { Kuczynski } \\
\text { / Martín } \\
\text { Vizcarra }\end{array}$ \\
\hline $\begin{array}{l}\text { Total de } \\
\text { renegocia- } \\
\text { ciones }\end{array}$ & 6 & 6 & 42 & 71 & 85 & 50 \\
\hline
\end{tabular}

Fuente: Cienfuegos 2019, 111.

Por su parte, Ruiz $(2015,8)$ estima que de 51 contratos suscritos hasta el año 2011 en materias de energía, irrigación, agua y saneamiento y transporte, más del $50 \%$ tenía dos o más renegociaciones. Por eso, acertadamente, concluye que la renegociación en el Perú, más que una excepción, se ha convertido en regla $(2015,9)$.

Por nuestra parte, al revisar los 95 proyectos APP adjudicados por Prolnversión entre 1998 y 2017, hemos encontrado que más del $70 \%$ de estos fue objeto de adendas ${ }^{(7)}$ y que existían, al menos, 45 adendas en proyecto a noviembre del $2018^{(8)}$

\section{Cuadro No. 2}

Modificación de los proyectos adjudicados

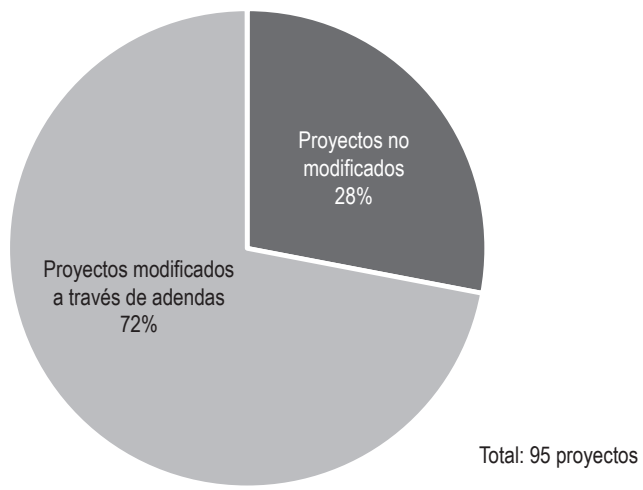

Cuadro No. 3

Proyectos modificados, por sectores

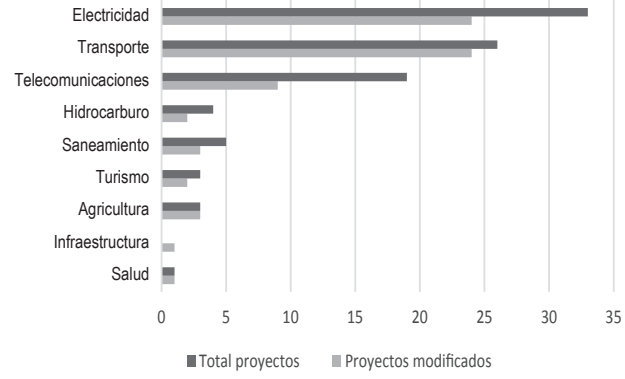

De otro lado, de acuerdo con Cienfuegos $(2019,110)$, el porcentaje de contratos con más de dos adendas supera el $51 \%$ del total de contratos de concesión adjudicados. En el caso de los sectores de transporte, irrigación y saneamiento, el porcentaje de contratos con más de 3 adendas representa entre el $50 \mathrm{y}$ el $80 \%$ del total.

\section{Cuadro No. 4}

Contratos de APP renegociados: Por número de adendas ( 0 a 3 o más)

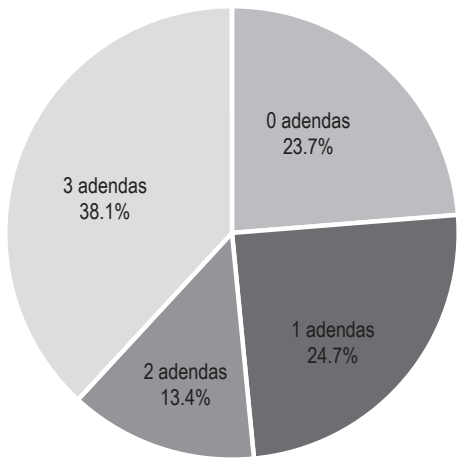

Fuente: Cienfuegos 2019, 111.

(7) En algunos casos, los proyectos APP comprenden la suscripción de más de un contrato de concesión, por lo que el número de contratos de concesión vigente a la fecha es mayor a 95

(8) Información obtenida de la revisión de los contratos de concesión APP suscritos entre 2011 y 2017 y de la información disponible en los portales web de Prolnversión, el Ministerio de Economía y Finanzas, Ministerio de Transportes y Comunicaciones, Ministerio de Energía y Minas, OSITRAN, OSIPTEL y OSINERGMIN, entre otros, a noviembre de 2018. 


\section{Contratos de APP renegociados: Por número de adendas (0 a 3 o más)}

\begin{tabular}{|l|c|c|c|c|c|}
\hline \multicolumn{1}{|c|}{ Sectores } & $\mathbf{0}$ adendas & $\mathbf{1}$ adenda & $\mathbf{2}$ adendas & $\begin{array}{c}\mathbf{3} \text { o más } \\
\text { adendas }\end{array}$ & Total \\
\hline Transporte & 4 & 7 & 4 & 16 & 31 \\
\hline Energía & 12 & 11 & 14 & 6 & 43 \\
\hline $\begin{array}{l}\text { Telecomunica- } \\
\text { ciones }\end{array}$ & 6 & 1 & 0 & 0 & 7 \\
\hline Irrigación & 0 & 1 & 0 & 3 & 4 \\
\hline Salud & 0 & 3 & 2 & 0 & 5 \\
\hline Turismo & 0 & 1 & 0 & 0 & 1 \\
\hline Saneamiento & 1 & 0 & 0 & 4 & 5 \\
\hline Justicia & 0 & 0 & 1 & 0 & 1 \\
\hline
\end{tabular}

Fuente: Cienfuegos 2019, 111

En línea con los hallazgos de la Contraloría, en nuestra investigación hemos encontrado que el promedio de adendas a los proyectos cofinanciados ha sido de 3.29 por contrato ${ }^{(9)}$; bastante superior al de los contratos autofinanciados, que fue de 1,31 por contrato ${ }^{(10)}$.

Debido, en gran medida, a esta problemática(11), el marco legal que rige las APP ha experimentado una serie de cambios y reglamentaciones (baste decir que la Ley de APP ha sido modificada cuatro veces en los últimos diez años ${ }^{(12)}$ ) con el propósito de asegurar una mejor planificación, formulación, adjudicación y ejecución de los proyectos desarrollados bajo dicha modalidad.

Ahora bien, la primera acción del Estado para intentar reducir el número de renegociaciones en contratos de APP fue introducir, en el Reglamento del Decreto Legislativo 1012, una prohibición a la celebración de adendas durante los primeros tres años (salvo ciertas excepciones). Como una disposición semejante no atacó las causas que las originaban, el efecto

\section{Cuadro No. 5 \\ Promedio de adendas en los contratos asociados a proyectos APP adjudicados desde el 2004}

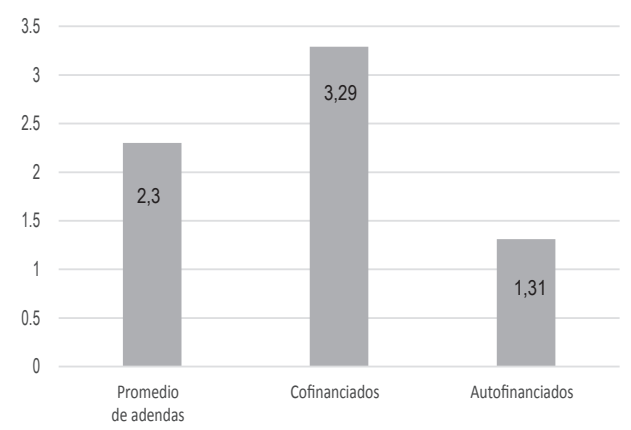

de la norma no fue significativo. Según la Contraloría $(2015,300)$ aproximadamente el $50 \%$ de renegociaciones de los contratos de concesión bajo la modalidad APP continuó realizándose dentro de los tres primeros años de su suscripción. A similar conclusión arriban Suto y otros. $(2013,88)$, quienes encuentran que el $57 \%$ de las adendas a los contratos de concesión de infraestructura de transporte analizados se suscribieron antes de los tres años.

La poca eficacia de la prohibición reglamentaria de celebrar adendas se explica cuando se analizan las excepciones previstas en el Reglamento del Decreto Legislativo $1012^{(13)}$. Estas admitían no sólo la modificación de errores materiales, sino

(9) Para obtener este promedio hemos identificado 79 adendas en 24 contratos asociados a proyectos cofinanciados adjudicados desde el año 2004, cuando fue adjudicada la primera concesión cofinanciada, hasta el 2017. Como ejemplo de las múltiples adendas en los contratos de proyectos cofinanciados indicamos aquellos que tienen más adendas: (i) el contrato de Tramos Viales del Eje Multimodal del Amazonas Norte del "Plan de Acción para la Integración de Infraestructura Regional Sudamericana - IIRSA Norte Paita-Yurimaguas" tiene 7 adendas; (ii) el contrato del Corredor vial Interoceánico Sur, Perú Brasil: Tramo 2 tiene 8 adendas; (iii) el contrato del Corredor vial Interoceánico Sur, Perú Brasil: Tramo 3 tiene 7 adendas; (iv) el contrato del Corredor vial Interoceánico Sur, Perú Brasil: Tramo 4 tiene 7 adendas; (v) el contrato del Primer Grupo de Aeropuertos de Provincia de la República del Perú tiene 8 adendas; y (vi) el contrato de Obras Mayores de Afianzamiento Hídrico y de Infraestructura para Irrigación de las Pampas de Siguas (Majes-Siguas II) tiene 12 adendas.

(10) Para obtener este promedio hemos identificado 88 adendas en 67 contratos asociados a proyectos autofinanciados adjudicados desde el año 2004 hasta el 2017.

(11) Debe reconocerse, sin embargo, que este fenómeno no es exclusivo de nuestro país. Un análisis de casi 1000 concesiones adjudicadas en 17 países de América Latina y El Caribe durante 1985-2000 para infraestructuras de agua y saneamiento, telecomunicaciones, energía y transporte, identificó que aproximadamente el $29.8 \%$ de los contratos de concesión en la región fueron modificados y, cuando se excluye el sector telecomunicaciones (en su mayoría, privatizado), la cifra se incrementa a 41.5\% (Guasch 2005, 31).

(12) La primera Ley de APP fue aprobada por el Decreto Legislativo 1012, publicado el 13 de mayo de 2008. El 29 de mayo de 2015 se publicó el Decreto Legislativo 1224, modificado por el Decreto Legislativo1251, del 30 de noviembre de 2016 . El 23 de julio de 2018 se publicó el Decreto Legislativo 1362, vigente desde octubre del 2018, con la publicación de su Reglamento.

(13) Que, además, fueron modificadas hasta en cinco oportunidades (Decretos Supremos 146-2008-EF; 106-2011-EF; 144-2009-EF; 127-2014-EF; y 376-2014-EF). 
también los cambios requeridos por los acreedores permitidos para alcanzar el cierre financiero (la famosa "adenda de bancabilidad"). Posteriormente, se agregaron las excepciones relativas a las "precisiones" de aspectos operativos y la necesidad de adelantar el programa de inversiones.

Salvo por los errores materiales (y, en algunos casos, la necesidad de adelantar el programa de inversiones), el resto de supuestos de excepción a la prohibición de celebrar adendas durante los primeros tres años no tenía su origen en causas imprevisibles, ni siquiera sobrevinientes. De hecho, la adenda de bancabilidad se convirtió en la norma de prácticamente todas las concesiones, puesto que Prolnversión se negó a incorporar en el texto de los contratos de concesión a ser adjudicados cláusulas exigidas por las entidades financieras previamente y que, justamente, fueron la causa de las adendas de bancabilidad.

Así, si bien se quiso evitar la suscripción de adendas a los contratos de concesión incorporando una limitación reglamentaria ( $\mathrm{y}$, por cierto, ilegal $\left.{ }^{(14)}\right)$ lo cierto es que sólo resolviendo los problemas de fondo que las gatillaban era posible cambiar dicha situación.

\section{Contratos incompletos: imprevisibilidad, mutabilidad y oportunismo}

La teoría del contrato incompleto postula que, debido a los altos costos de transacción que supondría abordar todas las contingencias posibles en un contrato de concesión, es inevitable que este sea incompleto, en mayor o menor medida.

Como ha enfatizado la literatura económica ${ }^{(15)}$, por tratarse de contratos de larga duración ${ }^{(16)}$, usualmente bajo la modalidad Build, Operate, Transfer (BOT) o Build, Own, Operate, Transfer (BOOT), que involucran un conjunto de prestaciones complejas, los contratos de concesión son necesariamente incompletos, pues no es posible contemplar todas y cada una de las vicisitudes que puedan suscitarse durante la vida de la concesión. A mayor plazo y complejidad de las prestaciones, mayor será el riesgo de que no prevean todos los aspectos ni contingencias que se presentarán durante su ejecución.

Adicionalmente, el concesionario debe asumir el riesgo derivado de que su objeto comprende la ejecución de inversiones significativas que devienen en costos hundidos; en tanto que el concedente debe asumir, en las diferentes etapas del proceso (formulación, licitación, ejecución), las consecuencias de la asimetría en la información sobre el negocio del concesionario, particularmente en lo que respecta al costo del servicio, la demanda y otras variables relevantes del proyecto.

En este escenario, es evidente que la renegociación sirve para remediar resultados subóptimos, derivados de equivocaciones de las partes en relación con un contrato complejo, así como de la omisión de regular los escenarios que terminan por presentarse (Guasch 2005, 96). En estos casos, la renegociación se convierte en una herramienta que, bien utilizada, garantiza la continuidad y correcta prestación del servicio, permitiendo subsanar cualquier error u omisión originarios.

Por ello, la doctrina ha destacado el carácter mutable del contrato de concesión, al que le es aplicable el principio de flexibilidad contractual. Este "tiende a la prevalencia del fin de interés público perseguido concretamente en cada caso" (Cassagne 1999, 68) sobre la rigidez de los términos originalmente pactados.

No debe olvidarse que las renegociaciones se producen no sólo a requerimiento del concesionario, sino que tradicionalmente ha sido el concedente quien ha promovido la modificación de la concesión cuando el interés público así lo exigía. De ahí surge la potestas variandi, reconocida por la doctrina al concedente como instrumento del cual ha de servirse para preservar el interés público, que es el fin de toda concesión de infraestructura o servicio público:

"la Administración puede verse en la necesidad -por razones de interés público- de introducir modificaciones al contenido del contrato originario (ej.: modificaciones tecnológicas, condiciones ambientales, seguridad del servicio por aumento del tráfico, etc.). Como se ha señalado, lo único inmutable en esta materia y que no se puede modificar es el fin del contrato administrativo que prevalece sobre el alcance y modalidad de

(14) Desde un inicio, la limitación de los tres (3) años para renegociar un contrato APP ha sido recogida en normas con rango reglamentario, no en una norma con rango legal.

(15) Por ejemplo, Ruiz (2015) y Guasch (2005).

(16) Cuyo plazo de vigencia puede ser hasta de sesenta años en el Perú. 
las prestaciones, siempre que la "equivalencia económica" de dichas prestaciones se mantenga inalterada" (Cassagne 1999, 67-68).

Siendo ello así, no es conveniente que la legislación limite, ciegamente, la posibilidad que mediante adenda puedan rectificarse errores iniciales plasmados en el texto original del contrato, máxime dada la complejidad de su diseño y sobre todo, porque de impedirse su corrección, será la sociedad la perjudicada. En palabras de García de Enterría y Fernández (citado por Cassagne 1999, 68):

"las exigencias del interés público, el servicio a la comunidad, no pueden quedar comprometidos por el error inicial de la Administración contratante o por un cambio en las circunstancias originalmente tenidas en cuenta al momento de contratar (...) Obligar a la comunidad a soportar una carretera, un puerto o un embalse mal planteado ab initio, inútiles e ineficaces desde una misma concepción, por un simple respeto al contractus lex, no tendría sentido. Al servicio del interés público y de sus concretas e insoslayables exigencias, el ius variandi de la Administración es ilimitado en extensión e intensidad, ya que el interés público prima sobre cualquier otra consideración."

En nuestra opinión, la prevalencia del interés público es el criterio que, en última instancia, debe primar cuando se analiza la procedencia de una adenda al contrato de concesión, sea que esta tenga su origen por iniciativa del concedente o del concesionario. Este criterio orientador debiera prevalecer y modular el mandato contenido en el artículo 55 de la Ley de APP(17), según el cual las modificaciones han de mantener "las condiciones de competencia del proceso de promoción". Lamentablemente, la Ley de APP no introduce este matiz, como tampoco su Reglamento, cuyo artículo $134^{(18)}$ no sólo reitera la importancia de mantener las "condiciones de competencia" sino que desarrolla, dentro los elementos para evaluarlas, a aquellas que fueron originalmente identificadas en el informe que sirvió de base a la versión final del contrato.

Lo conveniente, en nuestra opinión, sería que el Reglamento de la Ley de APP precisase que las condiciones de competencia del proceso de promoción se entenderán preservadas cuando existan elementos objetivos que evidencien que la modificación al contrato de concesión hubiera sido necesaria, con independencia de quién hubiera resultado adjudicatario del proyecto. A este criterio hay que agregar el tiempo transcurrido entre la suscripción del contrato y su renegociación, pues mientras mayor sea este, menor relevancia tendrá el principio de igualdad de los postores (mantener las condiciones de competencia del proceso de promoción) $)^{(19)}$.

Estas precisiones son importantes pues, como se verá más adelante, todos los estudios efectuados sobre las renegociaciones de los contratos de concesión de obra en el Perú coinciden en que, en su mayoría, estas tienen su origen en defectos de diseño (estudios técnicos inexistentes, insuficientes o deficientes, pobre técnica contractual, plazos para el cumplimiento de las prestaciones de cargo del concedente y del concesionario que no se condecían con la realidad, etc.).

(17) 55.1 El Estado, de común acuerdo con el inversionista, puede modificar el contrato de Asociación Público Privada, manteniendo su equilibrio económico financiero y las condiciones de competencia del proceso de promoción, conforme a las condiciones y requisitos que establece el Reglamento.

(18) "Artículo 134.- Modificaciones contractuales

134.1 Las partes pueden convenir en modificar el Contrato de APP, manteniendo el equilibrio económico financiero y las condiciones de competencia del Proceso de Promoción, procurando no alterar la asignación de riesgos y la naturaleza del proyecto.

134.2 En los procesos de modificación de Contratos de APP, la entidad pública titular del proyecto es responsable de sustentar el valor por dinero a favor del Estado, conforme lo establece el presente Reglamento, incluyendo la evaluación de las condiciones de competencia.

134.3 La evaluación de las condiciones de competencia se realiza sobre la base de la siguiente información:

Las condiciones de competencia del Proceso de Promoción previamente identificadas en el IEI que sustentó la VFC.

Las disposiciones establecidas en el Contrato.

Los hechos sobrevinientes a la adjudicación de la Buena Pro".

Las condiciones no imputables al Inversionista que afecten el desenvolvimiento del proyecto (...)

(19) "Desde luego que, para preservar los derechos de los oferentes que participaron en una licitación o concurso deben mediar circunstancias objetivas (aplicables cualquiera fuere el adjudicatario) y transcurrir un tiempo razonable a partir del perfeccionamiento del contrato" (Cassagne 1999, 68).

(20) "Artículo 110.- Aspectos técnicos del proyecto

110.1 Los Contratos pueden introducir la posibilidad de establecer optimizaciones en búsqueda de eficiencias y mejoras, ahorro de costos al Estado, reducción de necesidad de expropiaciones, reubicaciones o reasentamientos, mejoras en el método constructivo, entre otros, siempre que ello no conlleve la disminución de los Niveles de Servicio ni la calidad de la obra (...)". 
Consiguientemente, una aplicación ciega del artículo 55 de la Ley de APP, que prescinda del interés público, obligaría a la Administración a perpetuar los errores de origen, impidiéndole corregirlos, con el consiguiente agravio a la sociedad y, con frecuencia, al erario nacional.

En otras palabras, si bien el principio de igualdad de los postores es de gran trascendencia pues "si se incumple con el principio de igualdad, es virtualmente imposible el cumplimiento de otros como el de libre competencia y moralidad" (Morón y Aguilera 2014,331 ), se trata de un "derecho residual", que va perdiendo intensidad con el transcurso del tiempo (Cassagne 1999, 68).

Sin perjuicio de lo anteriormente señalado, un elemento que consideramos positivo en el Reglamento de la Ley de APP es la posibilidad prevista en su artículo $110^{(20)}$ de modificar las especificaciones del contrato para introducir optimizaciones en búsqueda de eficiencia y mejoras, siempre que ello no conlleve la disminución de la calidad de la obra ni de los niveles de servicio.

\section{Causas de renegociación}

Morón y Aguilera $(2014,325-328)$ han identificado como principales causas de renegociación, en contratos administrativos de larga duración, las siguientes ${ }^{(21)}$ :

a) La ocurrencia de un caso fortuito o de fuerza mayor. Como ejemplo del caso fortuito, mencionan al descubrimiento de riesgos arqueológicos, cuyo hallazgo no era previsible a la fecha de suscripción del contrato. Otros casos, como los desastres naturales (por ejemplo, los huaycos que asolaron nuestro país en el año 2017), son manifestaciones evidentes de caso fortuito, cuyo impacto pueden obligar a modificar los cronogramas de ejecución del proyecto e incrementar sus costos, afectando la distribución de riesgos en el contrato y su equilibrio económico financiero.

b) El cambio de prioridades del Estado respecto a cómo atender el interés público, lo cual puede generar perjuicios económicos al contratista y modificar el equilibrio económico financiero del contrato.

c) La necesidad de modificar un contrato para incluir avances tecnológicos ocurridos luego de su suscripción. Ello suele ocurrir en industrias como las telecomunicaciones, donde los cambios tecnológicos son frecuentes y sus consecuencias poco previsibles ${ }^{(22)}$.

d) La obligación de incluir nuevas normas técnicas, ambientales, tributarias, urbanísticas, o de otra índole, lo que puede alterar el equilibrio en cuanto a los riesgos asumidos por las partes.

e) Los errores en los estudios o expediente técnicos que sirven de sustento al contrato, lo que acarreará que el proyecto, o sus especificaciones, no sean los adecuados para satisfacer la necesidad pública que constituye su objeto.

f) El incumplimiento por el concedente de las obligaciones a su cargo. Un ejemplo frecuente -citado por Morón y Aguilera- es el retraso en la entrega o saneamiento de los terrenos necesarios para la ejecución del proyecto, lo que altera el cronograma de ejecución, compromete el financiamiento y ocasiona costos adicionales para el concesionario.

Ahora bien, para fines del presente artículo, hemos agrupado las causas de renegociación precedentemente reseñadas en dos: (i) aquellas que las partes, actuando diligentemente, no pueden razonablemente conocer o prever al momento de la suscripción del contrato (caso fortuito, fuerza mayor, cambio de prioridades o nuevos objetivos de interés público, cambios tecnológicos); y (ii) causas que, siendo previsibles, se originaron en deficiencias en el diseño del contrato, de sus especificaciones técnicas o del modelo de asignación de riesgos. Empecemos por analizar las primeras.

\subsection{Ius Variandi y Factum Principis}

Si bien estos dos supuestos tienen el mismo origen (actos del Estado que afectan la ecuación económica del contrato), difieren en que el ius variandi tiene que ver con el "'poder de intervención unilateral de una de las partes para imponer modificaciones en las mismas estructuras concesionales', y que incide normalmente en el régimen económico de la concesión"; en tanto que el factum principis consiste en un acto de gobierno (i.e. cambio en las leyes) "de índole económica", "que produce una alteración de la relación contractual perfeccionada entre el contratista y la Administración" (Mestre 1992, 73-75).

(21) Al respecto, véase Guasch (2005), Pérez Hualde (2009), Morón y Aguilera (2014), Ruiz (2015), Suto y otros (2013).

(22) Como ejemplo, es interesante mencionar que el contrato de la Red Dorsal Nacional de Fibra Óptica no contempló que el avance de la tecnología permitiría la expansión de redes privadas de fibra óptica de otros operadores que ahora se encuentran en competencia con el concesionario de la red dorsal y tienen tarifas más bajas que las estipuladas en el contrato de concesión. 
Es necesario precisar que la legislación peruana no admite el ius variandi (es decir, la modificación unilateral por el Estado) de un contrato de APP. Este, al igual que cualquier otro contrato, se encuentra protegido por lo dispuesto en el primer párrafo del artículo 62 de la Constitución ${ }^{23}$. Por ello el artículo 55 de la Ley de APP sólo contempla el supuesto de modificación de un contrato por mutuo acuerdo de las partes.

En cuanto a ejemplos del factum principis puede mencionarse el caso de la Línea de Transmisión MachupicchuQuencoro-Onocora-Tintaya, la cual, casi inmediatamente después de haber sido adjudicada en concesión, debió ser modificada debido a que el Estado decidió incorporar al Área de Conservación Regional Choquequirao parte de los terrenos por donde debía construirse la línea. Como consecuencia de ello, su puesta en operación comercial tuvo que ser postergada e incrementarse el monto de la inversión en USD 12,5 millones $^{(24)}$. Otros casos usuales son los cambios en las leyes tributarias, ambientales y laborales que afecten el equilibrio económico financiero de la concesión.

\subsection{Teoría de la Imprevisión}

La necesidad de modificar la concesión por causas sobrevinientes imprevisibles, irresistibles y extraordinarias, de manera que se asegure la continuidad del servicio público, ha sido admitida desde 1916. En ese año, en el Arrêt Gas de Burdeos, el Consejo de Estado francés aceptó reconocer a la concesionaria de alumbrado público de esa ciudad el derecho a una compensación por el incremento extraordinario del precio del carbón, que llegó a exceder la tarifa pactada en el contrato de concesión (Mestre 1992, 70) debido a la ocupación alemana de las principales zonas productoras y al bloqueo marítimo de sus puertos. Esta jurisprudencia reconoció que en supuestos de excesiva onerosidad de la prestación por causas sobrevinientes, el principio de continuidad de los servicios públicos obligaba a indemnizar al contratista para permitir que continuase con la ejecución del contrato. (Cassagne 1994, 966). Ante el surgimiento de lo imprevisto, sólo cabía aceptar la renegociación como vía para preservar el interés público, causa primigenia de la concesión.

Vale aquí precisar que para la aplicación de la teoría de la imprevisión se exige la concurrencia de los mismos requisitos que para la fuerza mayor (extraordinariedad, imprevisibilidad e irresistibilidad) con la diferencia que, en la primera, la prestación no deviene en imposible, sino en excesivamente onerosa.

Llama la atención que, a pesar de ser una causal pacíficamente aceptada por la doctrina desde los tiempos del Arrêt Gas de Burdeos, nuestra legislación ha excluido al caso fortuito de los supuestos que dan lugar al restablecimiento del equilibrio económico -mediante la correspondiente modificación contractual-. En efecto, de acuerdo con el artículo 37 del Reglamento de la Ley de APP, sólo es posible pactar el restablecimiento del equilibrio económico financiero originado en el cambio de las leyes aplicables ${ }^{(25)}$ (es decir, por los hechos del príncipe). En el supuesto de un caso fortuito, lo único que permite esa norma es ampliar los plazos, además de suspender las obligaciones de la parte afectada por el caso fortuito o hecho determinante de tercero.

\subsection{Otras causas de renegociación}

Como demuestran las múltiples investigaciones sobre este tema, la mayor parte de las adendas no tuvo su origen en causas sobrevinientes o imprevisibles, sino que fue consecuencia de errores y deficiencias en el diseño y estructuración del contrato, incluyendo la ausencia de estudios técnicos adecuados, una asignación de riesgos ineficiente y plazos poco realistas para la ejecución por el Estado y el concesionario de las prestaciones a su cargo.

En efecto, la literatura analizada (particularmente, los estudios de la Contraloría General de la República, Suto y otros, Céspedez y Paz, Benavente y Segura, EY) ha identificado que la gran mayoría de adendas a los contratos de concesión en el Perú obedeció a tres causas: (i) asuntos vinculados al expediente técnico de las obras y aspectos

(23) Artículo 62.- La libertad de contratar garantiza que las partes pueden pactar válidamente según las normas vigentes al tiempo del contrato. Los términos contractuales no pueden ser modificados por leyes u otras disposiciones de cualquier clase. Los conflictos derivados de la relación contractual sólo se solucionan en la vía arbitral o en la judicial, según los mecanismos de protección previstos en el contrato o contemplados en la ley (...).

(24) OSINERGMIN. 2018. Línea de Transmisión 220 kV Machupicchu-Cotaruse-Abancay. Ver https://www.osinergmin.gob.pe/seccion/ centro documental/electricidad/Documentos/PROYECTOS\%20GFE/Acorde\%C3\%B3n/Transmisi\%C3\%B3n/1.2.5.pdf.

(25) Artículo 37.- Restablecimiento del equilibrio económico financiero

37.1 Los Contratos pueden incluir disposiciones sobre el equilibrio económico financiero en las que se precise que su restablecimiento puede ser invocado por cualquiera de las partes, únicamente cuando éste se vea afectado significativamente debido al cambio de leyes aplicables, en la medida en que dichos cambios tengan impacto directo con aspectos económicos o financieros, vinculados a la variación de ingresos o costos asumidos por el Inversionista (...). 
operativos; (ii) bancabilidad del proyecto; y (iii) saneamiento de terrenos y liberación de interferencias. Además de dichas causas, creemos que es necesario considerar dos adicionales que, en nuestra opinión, pueden ser deternminantes en el caso de renegociaciones futuras: (iv) la viabilidad social y ambiental del proyecto; y (v) el uso y abuso de la modalidad de concursos de proyectos integrales, particularmente en el caso de APP cofinanciadas. Veamos cada una de ellas.

\subsubsection{Estudios técnicos insuficientes}

La Contraloría ha identificado que la principal causa de renegociación de los contratos de concesión analizados fue la necesidad de modificar o complementar las especificaciones técnicas de las obras, así como aspectos operativos vinculados a estas $(2015,277,299-300)$. En la mayoría de los casos, las adendas fueron consecuencia de la inexistencia o insuficiencia de los estudios de preinversión (factibilidad, ingeniería básica, ambientales, geológicos, etc.) efectuados por la entidad licitante, lo que determinó que existieran una serie de errores en el diseño del proyecto y en la asignación de riesgos que debieron ser posteriormente corregidos. Como afirman Céspedez y Paz (2018, 156):

“(...) dentro de esta categoría de modificaciones se incluyen a las adendas referidas a las variaciones de metrados y de obras adicionales, que han sido determinantes para el incremento sustancial de los compromisos presupuestales del concedente. Estas adendas no son ni necesariamente provechosas ni necesariamente perniciosas. Sin embargo, su celebración, sobre todo en el caso de las adendas sobre variaciones de metrados, no ha sido el producto de una renegociación orientada a la solución de contingencias no previsibles, sino para viabilizar un proyecto que presentaba deficiencias de origen en los estudios técnicos, así como en el diseño de la obra bajo la modalidad de precios unitarios. Como ya se ha señalado en el estudio de dichas modificaciones, los proyectos se concesionaron con estudios sin la suficiente información técnica requerida, lo que provocó la existencia de diferencias considerables y evitables entre los montos del proyecto referencial y los montos ejecutados."

De acuerdo con la Association of Advancement of Cost Engineering, a menor nivel de detalle de los estudios de un proyecto, mayor es la posibilidad de que los costos reales durante su construcción y operación varíen sustancialmente, producto de deficiencias o inconsistencias (EY 2016, 76). Tomando como base esta premisa, EY $(2016,73)$ concluye que 35 de las 39 adendas evaluadas por la Contraloría (es decir, el $90 \%$ ) tuvo su origen en aspectos que pudieron haberse previsto en los contratos de concesión, de haberse contado un mayor nivel de detalle del proyecto que permitiese identificar y asignar adecuadamente los riesgos.
Por su parte, Benavente y Segura (2017, 46) encuentran que en el caso de los contratos de concesión del sector transportes, el $58 \%$ de las adendas responde a temas operativos y el $9 \%$ a obras adicionales.

Es recién en el 2015, con el Decreto Supremo 410-2015-EF, que se busca resolver esta problemática, exigiendo un mayor nivel de análisis mediante la exigencia de la información mínima que debe tener el Informe de Evaluación que elabora la entidad que promueve un proyecto como APP. Luego, el Decreto Supremo 68-2017-EF incorporó información mínima adicional.

La regulación vigente actualmente recoge los cambios anteriores y define al Informe de Evaluación como el documento que elabora la entidad licitante (Organismo Promotor de la Inversión Privada - OPIP), sobre la base de estudios técnicos que contienen la información necesaria para: i) definir si es técnica, económica y legalmente conveniente desarrollar el proyecto como APP, ii) estructurar el proyecto y detectar contingencias significativas que pudieran retrasar el Proceso de Promoción, vinculadas principalmente a aspectos legales, financieros y técnicos, iii) delimitar competencias de gestión de la entidad pública. Asimismo, recoge lo dispuesto previamente sobre la información mínima que debe contener el Informe de Evaluación y agrega puntos adicionales, tal como realizar el análisis de valor por dinero, a través de la aplicación de los criterios de elegibilidad ${ }^{(26)}$.

\subsubsection{Bancabilidad}

Una de las causas recurrentes de renegociación de los contratos de concesión ha sido la vinculada a la bancabilidad del proyecto APP. En palabras de Zúñiga (2012, 264):

“(...) la bancabilidad del proyecto consistirá en determinar si este es capaz, en un determinado plazo de tiempo, de generar los recursos suficientes para repagar con dichos recursos el financiamiento otorgado por el prestamista. A tales efectos, el prestamista incluirá como parte del análisis de bancabilidad una evaluación financiera, técnica y jurídica del proyecto."

(26) Artículo 44 del Reglamento de la Ley de APP. 
Los contratos de concesión, usualmente, asignan al concesionario el riesgo de obtener el financiamiento necesario para ejecutar el proyecto(27), estipulando un plazo para acreditarlo.

Para asegurar este financiamiento es importante que la asignación de riesgos prevista en el contrato sea lo más precisa posible y que, con anterioridad al cierre del crédito, el concesionario esté en capacidad de constituir las garantías sobre los bienes, derechos y flujos de ingresos exigidos por los bancos y bonistas en una operación de crédito pactada bajo la modalidad de project finance. Adicionalmente, los bancos suelen exigir la inclusión de ciertas cláusulas que aseguren su derecho a subsanar cualquier incumplimiento del concesionario frente al concedente, así como a subastar la concesión a terceros si aquél incumple con las condiciones del crédito (conocidas como step-in rights).

Una de las modificaciones contractuales más frecuentes en esta materia fue complementar la definición de acreedores permitidos, así como los derechos que les eran reconocidos. Al respecto, Suto y otros $(2013,124)$ han identificado que el $62.5 \%$ de las adendas analizadas ${ }^{(28)}$ versaba sobre la modificación de la definición de acreedores permitidos; el $50 \%$ se refería a las garantías que podían constituirse en su favor; y el $25 \%$, a los step-in rights.

De acuerdo con las investigaciones de Céspedes y Paz (2018, 82-89) y de Suto y otros (2013, 96-99), otra razón para suscribir adendas de bancabilidad fue para incorporar el Certificado de Reconocimiento de derechos sobre el Pago Anual por Obras (CRPAO), el cual viabilizó, en su momento, la bancabilidad de ciertos proyectos de infraestructura de transporte público ${ }^{(29)}$. En otro sector (el de saneamiento), las dos primeras adendas al contrato de concesión del proyecto Derivación HuascacochaRímac se originaron en la necesidad de dar viabilidad financiera al contrato, pues no lograba alcanzar el cierre financiero (Contraloría General de la República 2015, 233).

Adicionalmente, EY $(2016,59)$ ha identificado que el Perú es uno de los países donde alcanzar el cierre financiero toma más tiempo desde la adjudicación de la APP. Ello denota que el contrato no ha sido adecuadamente diseñado para facilitar su financiamiento.

A pesar de que las cláusulas de bancabilidad son relativamente estándares, buena parte de estas no fueron incluidas en los contratos licitados por Prolnversión, incluso luego de las frecuentes adendas derivadas de dicha omisión. Ello contribuyó a que la renegociación del contrato, casi inmediatamente después de haber sido suscrito, para incorporar la "adenda de bancabilidad", se convirtiera en norma; a tal punto que la Contraloría la identificó como la segunda razón de renegociación contractual $(2015,284)^{(30)}$. No puede dejar de llamar la atención este hecho, cuando la necesidad de incluir cláusulas de bancabilidad adecuadas es uno de los elementos usuales en contratos de esta naturaleza.

Más sorprendente aún es que Prolnversión, con la excusa de no dilatar el proceso, se negara sistemáticamente a mejorar sus cláusulas de bancabilidad, a pesar de las frecuentes renegociaciones a que dieran lugar y que los postores frecuentemente solicitaban mejorar su redacción.

Paralelamente, tanto el Reglamento del Decreto Legislativo 1012 como el Reglamento del Decreto Legislativo 1224 admitieron como excepción a la prohibición de renegociar el contrato dentro de los primeros tres años a los "requerimientos sustentados de los acreedores permitidos, vinculados a la etapa de cierre financiero del contrato", con lo cual Prolnversión sabía que las cláusulas que se negaba a incluir podrían ser incorporadas luego mediante una "adenda de bancabilidad".

Es recién con la aprobación del Decreto Supremo 068-2017-EF que se exigió a Prolnversión o a la entidad licitante competente un "análisis preliminar de la bancabilidad". Simultáneamente, dicha norma eliminó las cláusulas de bancabilidad de la lista de excepciones permitidas a la prohibición de renegociación durante los primeros tres años.

5.3.3. Saneamiento de terrenos y liberación de interferencias

Otra de las causas frecuentes de renegociación de contratos de concesión ha sido la imposibilidad del Estado de cumplir

(27) Aparte de que esto es la práctica recurrente, la asignación al concesionario del riesgo de obtener financiamiento es una práctica recomendada en los Lineamientos de Asignación de Riesgos en los contratos de APP, aprobados por Resolución Ministerial 1672016-EF/15.

(28) Se analizaron las adendas de ocho (8) contratos de concesión en infraestructura de transporte bajo la modalidad APP.

(29) Por ejemplo, la adenda número 3 al contrato de concesión IIRSA Sur, Tramo 2: Urcos-Inambari, suscrita durante el primer año de suscrito el contrato de concesión (Contraloría 2015, 181-184).

(30) En esta línea también están Suto y otros (2013, 99-99); EY (2016, 11, 12, 60-62); y Benavente y Segura (2017, 46). 
con los plazos estipulados para el saneamiento y entrega de los terrenos requeridos para el proyecto, así como para la liberación de interferencias.

Es práctica usual en proyectos APP -recomendada, además, por los Lineamientos de Asignación de Riesgos ${ }^{(31)}{ }_{-}$ que el riesgo vinculado a la entrega de terrenos y liberación de interferencias sea asignado al Estado, ya que teóricamente se encuentra en mejor posición para cumplir con dicha obligación (particularmente, porque es quien tiene el poder de expropiar los terrenos y emitir las normas legales que regulan la liberación de interferencias). Sin embargo, en la práctica, los propios Lineamientos reconocen que el concesionario puede ser más eficiente que el concedente $y$, consiguientemente, compartir el riesgo del saneamiento de terrenos ${ }^{(32)}$.

En múltiples ocasiones, el Estado peruano no ha podido cumplir con los plazos estipulados en los contratos de concesión para sanear los terrenos y liberarlos de interferencias. Esto resulta sorprendente, teniendo en cuenta que dichos plazos fueron fijados por el propio concedente, que elaboró los contratos (EY 2016, 13). En gran parte de los casos, el problema tuvo su origen en la fijación de plazos poco realistas que no tomaron en cuenta el estado del saneamiento físico-legal de los predios al momento de la suscripción de los contratos.

De hecho, con anterioridad al Reglamento del Decreto Legislativo 1224 (que entró en vigencia en el año 2015) la entidad licitante ni siquiera estaba obligada a efectuar un reconocimiento previo de la zona destinada al desarrollo el proyecto. Es decir que al momento de suscribir el contrato y pactar los plazos de entrega de terrenos, el Estado ni siquiera tenía una idea aproximada de la situación físico legal de los terrenos como tampoco de los plazos y acciones estatales necesarios para cumplir con sus obligaciones.

Esta situación llevó a la Contraloría $(2015,284)$ a concluir que "es probable que los estudios técnicos que se elaboraron para determinar dichos plazos no tenían datos certeros que permitan establecer fechas seguras para la culminación del saneamiento legal de los terrenos". Así, la ausencia de análisis suficiente ha conducido a pactar cláusulas imposibles de cumplir por el Estado y, en consecuencia, a la necesidad de continuas renegociaciones del cronograma de ejecución del proyecto.

El proyecto Longitudinal de la Sierra, Tramo 2, es un buen ejemplo de lo señalado precedentemente. El concedente se demoró en entregar los predios debidamente saneados que eran necesarios para ejecutar algunos tramos de la vía. Incluso varios de los terrenos entregados tampoco cumplían con estar libres de interferencias o debidamente saneados. Todo lo anterior generó retrasos en la ejecución de las inversiones y la paralización parcial de las obras ${ }^{33}$. Actualmente, el Estado viene negociando una modificación a la asignación de riesgos del contrato, de modo que el concesionario los asuma parcialmente y se encargue de culminar las expropiaciones pendientes ${ }^{(34)}$. Evidentemente, el incumplimiento del Estado lo obliga a indemnizar el daño emergente y el lucro cesante ocasionado al concesionario, elevando el costo del proyecto y retrasando la ejecución de una obra de interés público.

Otro ejemplo paradigmático es la ampliación del aeropuerto Jorge Chávez. En este caso, la entrega de los terrenos sufrió hasta seis postergaciones ${ }^{(35)}$. Asimismo, la Línea 2 del Metro de Lima ha visto retrasada su ejecución por la falta de saneamiento de los terrenos. Como consecuencia de ello, en el año 2018 la inversión ejecutada en este proyecto representó sólo el $72 \%$ de lo programado, retrasando una inversión de

(31) Aprobados mediante Resolución Ministerial 167-2016-EF/15.

(32) El artículo 23 de la Ley Marco de Expropiaciones, Decreto Legislativo 1192, prevé la posibilidad que el inversionista pueda adquirir los predios en trato directo, antes de que la entidad licitante inicie la expropiación. La solución de incluir al concesionario en la liberación de las áreas necesarias para el proyecto se ha implementado en algunas ocasiones; por ejemplo, en la adenda 5 al contrato de concesión de IIRSA Sur tramo 3, que incorporó al concesionario en la ejecución de las actividades necesarias para la liberación de los terrenos.

(33)OSITRAN. Informe de Desempeño 2017 Longitudinal de la Sierra Tramo 2: Ciudada de Dios - Cajamarca - Chiple - Cajamarca - Trujillo - Dv. Chilete - Emp. PE3N; y ANDINA. 2018. https://andina.pe/agencia/noticia-mtc-culminara-los-pagos-liberacion-terrenospara-via longitudinal-de-sierra-720686.aspx (11 de agosto de 2018).

(34) Véase https://larepublica.pe/sociedad/1241019-mtc-coordina-ejecucion-tramos-pendientes-longitudinal-sierra (12 de mayo de 2018). Cabe señalar que la empresa parecería estar de acuerdo y ha proyectado en su plan de negocios cooperar con el Estado peruano en la liberación de terrenos para nuevos peajes. Ver: Plan de Negocios 2017 de Concesionaria Vial Sierra Norte. (https://www.ositran.gob.pe/joomlatools-files/docman-files/RepositorioAPS/0/0/par/000001-).

(35) Debido a ello, el concesionario Lima Airport Partners y el Ministerio de Transportes y Comunicaciones han suscrito siete adendas, la última celebrada doce años después de suscrito el contrato de concesión. Recién el 24 de octubre de 2018, el Estado entregó al concesionario los terrenos completos para la ampliación del terminal aéreo (https://elcomercio.pe/lima/transporte/ejecutivo-entregaterrenos-ampliar-jorge-chavez-18-anos-espera-nndc-noticia-570798). 
S/.496 millones de soles que resulta prioritaria para la ciudad de Lima (Reyes 2018).

La falta de rigor del Estado para fijar plazos contractuales razonables y desplegar sus mejores esfuerzos para cumplir con sus compromisos es de suma gravedad, pues en muchos casos constituye una causal de caducidad de la concesión por incumplimiento del concedente, que obliga a indemnizar al inversionista y pone en riesgo la viabilidad del proyecto en los plazos requeridos. Además, usualmente los bancos no están dispuestos a asumir el riesgo de entrega de los terrenos saneados, por lo que no es posible alcanzar el cierre financiero en tanto no se acredite su cumplimiento, como tampoco será posible dar inicio al procedimiento destinado a obtener la certificación ambiental.

Otro aspecto adicional es que el incumplimiento por el concedente de sus obligaciones afecta la credibilidad del Estado frente a los inversionistas y la población, así como incentiva el conflicto social vinculado al saneamiento de terrenos.

Recién en el año 2015, con la publicación del Reglamento del Decreto Legislativo 1224, el Estado decidió atacar algunas de las causas del retraso en el saneamiento de terrenos y liberación de interferencias, incorporando dentro de las obligaciones de la entidad licitante la de efectuar un diagnóstico técnico legal sobre el estado de propiedad de los inmuebles, bienes y derechos necesarios para el desarrollo del proyecto, incluyendo las interferencias y una estimación de su valorización, a ser incorporado en el Informe de Evaluación. Posteriormente, el Decreto Supremo 068-2017-EF agregó la obligación de establecer un cronograma para la liberación de interferencias y el saneamiento de los predios. Asimismo, el Decreto Legislativo 1251, norma que modificó el Decreto Legislativo 1224 en noviembre del 2016, dispuso que en el Informe de Evaluación debía fijarse el porcentaje de predios y áreas a ser liberado, como requisito previo para la adjudicación del proyecto.

Por su parte, la vigente Ley de APP y su flamante reglamento contemplan, entre otras, lo siguiente: (i) mantiene la obligación de fijar en el Informe de Evaluación la meta de liberación de predios y de interferencias que debe cumplirse como requisito para la adjudicación del proyecto, bajo responsabilidad; (ii) se obliga a la entidad titular del proyecto a iniciar tempranamente el proceso de saneamiento de terrenos y liberación de interferencias, bajo responsabilidad; y (iii) se le faculta a realizar procesos de reubicación o reasentamiento.

De otro lado, se ha aprobado un marco normativo más sencillo para las expropiaciones y liberaciones de terrenos ${ }^{(36)}$, a fin de reducir los plazos del proceso.

Más allá de la eficacia de estas disposiciones, cabe preguntarse si una de las razones para el incumplimiento por el Estado de sus obligaciones es que las expropiaciones son impopulares, motivo por el que muchos funcionarios evitan realizarlas ${ }^{(37)}$, sobre todo cuando hay necesidad de reubicar pobladores. Por ello, para mitigar de manera efectiva el riesgo de incumplimiento del concedente en esta materia, es importante obligarlo a alcanzar la meta de liberación de predios, como requisito para su adjudicación. De esta manera, se evitarán los costos y problemas derivados de la necesidad de renegociar nuevos plazos de entrega ${ }^{(38)}$.

5.3.4. Falta de análisis de la viabilidad social y ambiental del proyecto.

El éxito de un proyecto también depende de la gestión y el manejo de sus impactos sociales y ambientales. Según la Reference Guide de $A P P$ del PPP Knowledge $L a b^{(39)}$, organización perteneciente al Banco Mundial, la evaluación de proyectos de APP debe incluir el análisis de su sostenibilidad ambiental y social. Ello supone cumplir, como mínimo, con los estándares ambientales y de planificación nacionales y, deseablemente, con los Equator Principles, basados en estándares del International Finance Corporation, organización asociada al Banco Mundial.

(36) El marco normativo que ha facilitado la adquisición y expropiación de inmuebles, transferencias de inmuebles de propiedad del Estado, liberación de interferencias y otras medidas para la ejecución de obras de infraestructura, está conformado por el Decreto Legislativo 1192, publicado el 23 de agosto de 2015; y sus modificatorias aprobadas por el Decreto Legislativo 1330, publicado el 6 de enero de 2017 y el Decreto Legislativo 1366, publicado el 23 de julio de 2018.

(37) Viviana Gálvez Cordova, “¿Qué se necesita para facilitar la expropiación de terrenos?”. El Comercio, 11 de noviembre de 2015. En: https://elcomercio.pe/economia/peru/necesita-facilitar-expropiacion-terrenos-204178.

(38) Cabe señalar que el gobierno está adecuándose al nuevo marco normativo en APP. Por ejemplo, la Ley 30834 , publicada el 31 de julio de 2018, ha autorizado la expropiación de inmuebles para el proyecto "Sistema de Tratamiento de las Aguas Residuales de la Cuenca del Lago Titicaca", al amparo del Decreto Legislativo 1192. Esta autorización ha sido publicada al inicio del concurso convocado por Prolnversión, antes de la adjudicación del contrato, de manera que sea posible entregar terrenos liberados en los plazos previstos en el contrato de concesión.

(39) Véase https://pppknowledgelab.org/guide/sections/83-what-is-the-ppp-reference-guide. 
En efecto, el análisis de los impactos sociales y ambientales contribuye a identificar el proyecto más conveniente así como a su formulación más adecuada ${ }^{(40)}$. Además, una evaluación oportuna de la viabilidad ambiental y social ayuda a prevenir conflictos sociales durante la ejecución de los proyectos.

Sin embargo, como identifica Távara $(2017,71)$ el análisis de las externalidades negativas derivadas del impacto ambiental y social de los proyectos ha sido con frecuencia omitido en el caso peruano. Reflejo de lo anterior es que este aspecto fue soslayado en el marco legal de las APP, que remitió su regulación a los contratos de concesión, caso por caso.

Recién en el año $2015^{(41)}$, con la aprobación del Decreto Supremo 410-2015-EF (Reglamento del Decreto Legislativo 1224) se estableció la obligación de incluir en el Informe de Evaluación el análisis de los aspectos ambientales y sociales relevantes, identificando los problemas que pudieran retrasar el proyecto. Asimismo, se exigió realizar un análisis de rentabilidad social para los proyectos autofinanciados.

La nueva normativa de APP recoge la obligación de incluir aspectos ambientales y sociales relevantes en el Informe de Evaluación ${ }^{(42)}$. Asimismo, para las iniciativas privadas cofinanciadas, especifica que corresponde a la entidad pública respectiva realizar la formulación del proyecto, que comprende su evaluación económica y financiera, incluyendo una evaluación preliminar del impacto social, a fin de determinar si es económica y socialmente rentable ${ }^{(43)}$.

El propósito de la Ley de APP y el Reglamento vigentes es que durante la etapa de formulación del proyecto, la entidad licitante esta en capacidad de advertir contingencias vinculadas a temas ambientales o sociales que puedan demorarlo. La relevancia de estas disposiciones se evidencia en el hecho que la mayoría de conflictos sociales en nuestro país es de tipo socioambiental (62.4\%) (Defensoría del Pueblo) y que en el último año ha habido un promedio de 124 conflictos socioambientales activos.

Por ejemplo, es probable que el conflicto social acontecido durante la construcción de la Línea de Transmisión CarhuamayoParagsha-Conococha-Huallanca-Cajamarca-Cerro Corona-
Carhuaquero, que retrasó y limitó la ejecución de dicho proyecto, no hubiera ocurrido si el trazo de la línea, desde un inicio, hubiera excluido el tramo Cerro Corona-Carhuaquero. Sin embargo, esta exclusión sólo ocurrió después del conflicto social generado por dicha situación (Chamorro 2013, 168).

Otro aspecto de singular relevancia para evitar contingencias en la ejecución de proyectos de infraestructura es el cumplimiento del proceso de consulta previa a los pueblos indígenas y originarios. Este derecho fue incorporado al ordenamiento jurídico peruano con la entrada en vigor del Convenio 169 de la Organización Internacional del Trabajo, en el año 1995. La Ley 29785, Ley del derecho a la consulta previa a los pueblos indígenas u originarios, y su reglamento, aprobado por Decreto Supremo 001-2012-MC, desarrollan el contenido y el proceso de la consulta previa. De acuerdo con este marco normativo, los pueblos indígenas y originarios tienen derecho a ser consultados, previamente, sobre las medidas legislativas y administrativas susceptibles de afectar directamente sus derechos colectivos.

El caso de la Hidrovía Amazónica es un ejemplo que permite apreciar la magnitud de las consecuencias derivadas de incumplir la consulta previa. En el año 2013, Prolnversión convocó a un concurso de proyectos integrales para adjudicarla. No obstante, durante el proceso de promoción se admitió a trámite una demanda de amparo que exigía la realización de la consulta previa y el primer juzgado mixto de Nauta ordenó al Ministerio de Transportes y Comunicaciones y a Prolnversión la suspensión del proceso con el fin de realizar la consulta previa. Esta decisión judicial fue confirmada en segunda instancia ${ }^{(44)}$.

(40) Távara da un ejemplo muy interesante cuando menciona que el impacto ambiental y las externalidades negativas del despliegue de redes de transporte cerca de zonas ecológicamente vulnerables puede ser mayor en el caso de carreteras que de redes ferroviarias. Sin embargo, este factor frecuentemente no es tomado en cuenta en la evaluación por el Estado de la infraestructura más adecuada $(2017,71)$.

(41) Cabe señalar que una excepción a la falta de regulación de estos aspectos es el Decreto Supremo 127-2014-EF (antiguo reglamento de APP), cuyos artículos 20 y 21 establecían, en relación con las iniciativas privadas autofinanciadas, que debía haber una evaluación preliminar del impacto ambiental, y, de ser el caso, un plan de mitigación ambiental. No obstante, no estableció un mandato similar para las iniciativas estatales ni para las iniciativas privadas cofinanciadas.

(42) Artículo 44.2 del Reglamento de la Ley de APP.

(43) Artículo 108.5 del Reglamento de la Ley de APP.

(44) En cumplimiento de la decisión judicial, entre marzo y setiembre del año 2015, el Ministerio de Transportes y Comunicaciones consultó la propuesta de Resolución Directoral que aprueba los Términos de Referencia Finales para la elaboración del Estudio de Impacto Ambiental Detallado del proyecto Hidrovía Amazónica. En el proceso de consulta previa estuvieron involucrados 14 pueblos indígenas. 
Similar fue el caso del proyecto Línea de Transmisión Moyobamba-lquitos, cuya ejecución fue suspendida en agosto del 2018 por la Corte Superior de Justicia de Loreto, en tanto no se realizase el proceso de consulta previa ${ }^{(45)}$. Cabe señalar que este proyecto tampoco pudo implementarse debido a la desaprobación del Estudio de Impacto Ambiental. Esta línea de transmisión fue adjudicada por Prolnversión en junio del año 2014 y, como puede apreciarse, el tema socioambiental ha sido una de las razones principales de su retraso. Como consecuencia de ello, el Ministerio de Energía y Minas ha manifestado que volverá a evaluar todo el esquema de dicha línea de transmisión ${ }^{(46)}$.

\subsubsection{Uso y abuso del Concurso de Proyectos Integrales}

Tal vez, el resultado más relevante que ha arrojado nuestra investigación de las adendas a los contratos de concesión licitados por Prolnversión entre los años 1998 y 2017, es que los proyectos adjudicados bajo el mecanismo competitivo de Concurso de Proyectos Integrales (CPI) han tenido una cantidad de adendas mucho mayor que los proyectos adjudicados bajo Licitaciones Públicas Especiales (LPE). En efecto, del total de 258 adendas suscritas, 73 corresponden a contratos resultantes de LPE y 185 a CPI.

Por otra parte, 49 de un total de 65 proyectos adjudicados bajo la modalidad de CPI fueron objeto de renegociaciones, en tanto que 19 de un total de 30 contratos adjudicados mediante LPE fue objeto de adendas.

Cuadro No. 6

Porcentaje de adendas según la modalidad del proceso de promoción de la inversión privada

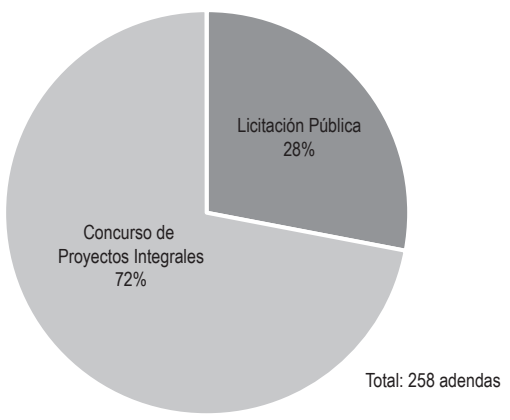

El mecanismo competitivo CPI procede cuando la entidad licitante no cuenta con los estudios a nivel definitivo para la ejecución de la obra o la explotación del servicio. En este caso, las propuestas que presentan los postores deben contener las condiciones contractuales, técnicas, económicas y financieras de la obra que se pretende ejecutar o el servicio que se pretende explotar. Por el contrario, la LPE se utiliza cuando la entidad licitante cuenta con los estudios requeridos para definir las especificaciones de la obra de servicio público o infraestructura que debe ejecutarse ${ }^{(47)}$.

Para la doctrina, la LPE debe ser la regla en el caso de iniciativas estatales, reservándose el $\mathrm{CPI}$ a las iniciativas privadas de complejidad técnica, en las que la empresa privada formula y estructura el proyecto, que posteriormente es declarado de interés por el Estado:

"Se considera además que se debe acudir a un Concurso de Proyectos Integrales cuando el postor tenga a su cargo el diseño y la tecnología a ser empleadas en construcción de la obra o la prestación o explotación del servicio público o cuando se limite a mejorar la infraestructura existente, mientras que se debe optar por una Licitación Pública cuando el diseño y tecnología a emplear ya se encuentran definidos por el Estado" (Shimabukuro 2013, 120).

"(...) cuando el Estado sabe lo que quiere y cómo lo quiere, confecciona un Pliego y llama a Licitación Pública. En cambio, cuando sabe lo que quiere pero no cómo lo quiere, especifica el objeto de la concesión (contenido de la declaración de interés público) y convoca a la presentación de iniciativas. Finalmente, cuando no sabe ni qué quiere ni cómo lo quiere, recepta iniciativas privadas y convoca a concurso de proyectos integrales" (Fanelli Evans citado por Mertehikian 1996, 1).

(45) Sentencia recaída en el Expediente No. 01130-2015-0-1903-JR-Cl-01. Cabe señalar que este proyecto también tiene serios cuestionamientos ambientales y sociales.

(46) Declaraciones del ex viceministro de Energía, Raúl García Carpio. 2018. (https://andina.pe/agencia/noticia-transmision-electricase-licitaran-hasta-seis-lineas-este-ano-700674.aspx).

(47) Las definiciones de CPI y LPE se encuentran en el artículo 5 del nuevo Reglamento de la Ley de APP. Prácticamente transcribe en los mismos términos la distinción recogida en el derogado Decreto Supremo 189-92-EF, que aprobó el Reglamento de las Inversiones Privadas en Obras de Infraestructura y en Servicios Públicos (artículos 8 y 9). 
Ahora bien, aunque el CPI surgió como consecuencia de la presentación de iniciativas privadas, la normativa peruana ha permitido su utilización para promover iniciativas estatales. En nuestra opinión, ello ha abierto la puerta para que Prolnversión lo utilice, de manera indiscriminada, para promover proyectos de iniciativa estatal en todos los sectores, particularmente en los cofinanciados. El abuso del CPI ha llegado a tal extremo, que el $68 \%$ de los proyectos APP se ha adjudicado mediante esta modalidad ${ }^{(48)}$.

En otras palabras, el Estado ha preferido transferir al privado la responsabilidad sobre el diseño y elaboración de los estudios técnicos, en lugar de invertir en estudios propios. Este abuso del CPI ha tenido como consecuencia que se suscriban contratos de concesión sin que el Estado cuente con estudios suficientes para asignar correctamente los riesgos, lo que ha propiciado la suscripción de múltiples adendas. Esta situación reviste mayor gravedad si se tiene en cuenta que el $\mathrm{CPI}$ es la modalidad más utilizada para adjudicar contratos de concesión cofinanciados ${ }^{(49)}$; es decir, aquellos en los que la ejecución de una parte sustancial del proyecto se financia con recursos públicos.

\section{Cuadro No. 7}

Modalidad de adjudicación de los proyectos cofinanciados

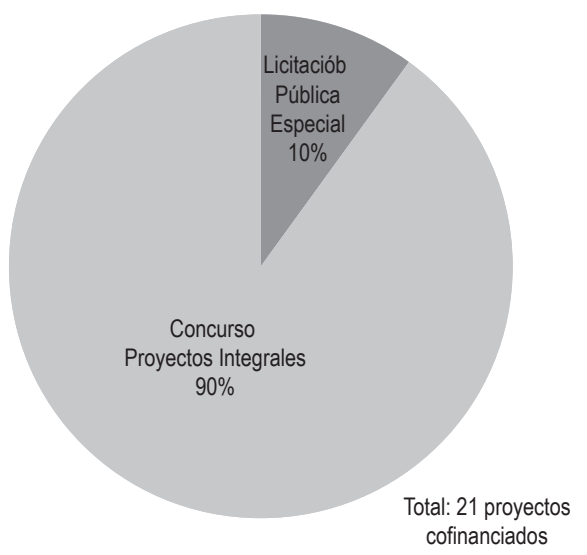

Entonces, al hecho de que el CPI permite adjudicar un proyecto sin contar con estudios mínimos suficientes, se le agrega la variable de que la mayoría de los proyectos financiados con fondos estatales son adjudicados de esta manera.
Este hallazgo está en línea con la investigación de Guasch $(2005,116)$, quien encontró que la renegociación de contratos cofinanciados es más frecuente que la de los autofinanciados: "Esta relación resulta un poco sorprendente, sin embargo, una explicación posible sería pensar que tener al gobierno de socio facilita las renegociaciones."

Si un contrato cofinanciado ya tiene mayor probabilidad de ser renegociado que uno autofinanciado, esta se multiplica cuando el Estado lo adjudica sin mayores estudios, mediante un $\mathrm{CPI}$.

Sin embargo, en ninguna de las múltiples normas que han regulado las APP se ha establecido requisito alguno para que proceda la utilización del mecanismo de $\mathrm{CPI}$; ni siquiera se exige a la entidad licitante que sustente su decisión de utilizarlo. El ordenamiento vigente únicamente exige que el plan de promoción del proyecto especifique si este se promocionará mediante una LPE, CPI o alguna otra modalidad(50). No conocemos de ningún plan de promoción que justifique las razones de la entidad licitante para elegir entre una u otra figura.

En nuestra opinión, la facilidad que otorga la regulación vigente para que el Estado licite contratos mediante $\mathrm{CPI}$, ha promovido que se lancen al mercado proyectos carentes de un adecuado análisis técnico, financiero, físico-legal, social y ambiental; todo lo cual ha impedido que la entidad licitante esté en capacidad de identificar y asignar de manera adecuada los riesgos entre las partes del contrato. Como consecuencia de ello, se ha creado un escenario en el cual, la imposibilidad de las partes para cumplir con sus obligaciones contractuales, así como la existencia de múltiples vacíos e inconsistencias en el texto del contrato hagan indispensable renegociarlo para continuar con la ejecución del proyecto. Lamentablemente, esta situación es más frecuente en el caso de los contratos cofinanciados.

(48) 65 de los 95 proyectos analizados han sido adjudicados mediante CPI.

(49) De acuerdo al artículo 31, numeral 1 del nuevo Reglamento de APP, el cofinanciamiento es cualquier pago que utiliza fondos públicos, total o parcialmente, a cargo de la entidad pública titular del proyecto para cubrir las obligaciones establecidas en el respectivo contrato.

(50) Artículo 47, numeral 1.2, del nuevo Reglamento de APP. 


\section{A modo de conclusión: algunos apuntes sobre el costo-beneficio de optar por las renegociaciones}

El análisis de las principales causas de renegociación de contratos de concesión en el Perú nos lleva a concluir que, en la mayor parte de los casos, la necesidad de suscribir adendas hubiera podido evitarse con una adecuada identificación y asignación de riesgos. Para ello, resulta indispensable contar con estudios adecuados, una Administración proactiva en el cumplimiento de las obligaciones de cargo del concedente y contratos que contemplen adecuadamente los aspectos relevantes y previsibles que pudieran suscitarse durante las distintas etapas de ejecución de la APP.

No es en vano, por ende, preguntarse por qué el Estado optó por el camino opuesto: licitando proyectos que carecían de estudios suficientes y terrenos saneados, incorporando cláusulas que habían demostrado sus limitaciones en casos anteriores. A continuación intentaremos dar una explicación de esta conducta que, a primera vista, parece poco racional.

\subsection{Los réditos políticos de adjudicar proyectos APP}

La adjudicación de un proyecto APP es un logro que los gobiernos nacionales, locales y regionales buscan capitalizar. El compromiso asumido por los gobernantes de turno con los grupos de interés en el mercado político y la influencia de estos sobre el comportamiento del gobierno representa una "inversión reputacional" que justifica la celebración de contratos de concesión, aun conociendo que han sido diseñados con base en estudios técnicos incompletos (Ruiz 2018, 21-23)(51).

Además, la adjudicación de una APP es percibida por la población como un indicador de reducción de la brecha de infraestructura existente, al canalizar inversión privada y pública para el desarrollo de proyectos y servicios esenciales. A fin de obtener el beneficio político de estos indicadores, tanto las entidades titulares de los proyectos (sectores y gobiernos regionales o locales) como las licitantes, tienen incentivos para que los procesos de promoción de la inversión privada y su adjudicación ocurran en el plazo más breve posible.

Las elecciones también pueden tener una incidencia significativa en la decisión del gobierno de postergar el análisis de ciertos temas para un momento posterior a la suscripción del contrato de concesión. Al respecto, Guasch $(2005,116)$ ha identificado que las renegociaciones son más comunes en los primeros años posteriores a una elección nacional. Ello puede deberse a que el gobierno saliente está más interesado en el rédito político de arrogarse el éxito de la adjudicación de la APP que en su viabilidad, optando por trasladar al gobierno siguiente la tarea de arreglar, o precisar, los errores que fueron producto de preferir los "tiempos políticos" a los "tiempos técnicos".

Por otro lado, la conducta de Prolnversión y otras entidades licitantes está alineada con su principal función: promover la inversión privada y culminar procesos de licitación exitosamente; es decir, adjudicar el mayor número de APP posible. Lo que ocurra luego de la celebración del contrato pasa a ser responsabilidad de una entidad distinta. Consiguientemente, sus incentivos están orientados a alcanzar el objetivo que sirve para medir el éxito de su gestión.

Por ejemplo, el Plan Operativo Institucional de Prolnversión del año 2018 estableció, como meta anual de la Dirección de Portafolio de Proyectos ${ }^{(52)}$, la adjudicación de 27 proyectos de promoción de la inversión privada ${ }^{(53)}$. Consiguientemente, los funcionarios de Prolnversión tienen todos los incentivos para priorizar el cumplimiento de esta meta ${ }^{(54)}$, en lugar de la compleción del contrato APP y su efectividad en el largo plazo. De hecho, no alcanzar la meta anual puede representar un costo político para los servidores públicos de la entidad licitante. No es de sorprender, en consecuencia, que para estas, tenga mayor peso cumplir con las metas de promoción de la inversión que contar con estudios y evaluaciones con el

(51) Para Ruiz, estas situaciones generarían que los concesionarios oportunistamente soliciten modificaciones contractuales, incluyendo cambios presupuestales, y que el concedente deba aprobarlas.

(52) De acuerdo al artículo 246 del Reglamento de Organización y Funciones de Prolnversión, la Dirección de Portafolio de Proyectos es el órgano encargado de la planificación y dirección de la gestión de los proyectos vinculados a los procesos de promoción de la inversión privada que le sean asignados en las fases de formulación, estructuración y transacción.

(53) Acción Estratégica Institucional 01.01, Dirección de Portafolio de Proyectos. (http://www.proinversion.gob.pe/RepositorioAPS/0/1/ JER/PLAN_POI/POI\%202018.pdf).

(54) Es más, en el año 2015, la Dirección de Promoción de Inversiones tenía como objetivos promover la participación de la inversión privada en determinados proyectos ya especificados en el Plan Operativo Institucional (por ejemplo, Longitudinal de la Sierra Tramo 4 y Obras de Cabecera y Conducción para el Abastecimiento de Agua Potable para Lima, postergados para el año 2019) (http:// www.proinversion.gob.pe/RepositorioAPS/0/1/JER/PLAN_POI/POI\%202015\%20v2.pdf). 
nivel de detalle suficiente como para efectuar una adecuada asignación de riesgos ${ }^{(55)}$.

En suma, el Estado peruano tomó una decisión oportunista al lanzar al mercado, deliberadamente, contratos deficientes e incompletos, a sabiendas de que ello lo iba a obligar a frecuentes renegociaciones. Su justificación fue política: cumplir con sus metas de promoción de la inversión privada y ser reconocido por el "éxito" de una gestión dedicada a reducir la brecha en infraestructura. Un ejemplo de lo anterior puede encontrarse en el caso del proyecto Línea de Transmisión Moyobamba-Iquitos que, sin contar con un análisis de viabilidad técnica ${ }^{(56)}$, social y ambiental, fue lanzado al mercado por razones políticas.

Otro caso interesante de estudio, aunque polémico, es el del corredor vial Interoceánico Sur (IIRSA Sur). Los contratos de concesión vinculados al proyecto IIRSA Sur son los que más adendas han tenido; lo que ha incrementado su costo en 600 millones de dólares más de lo originalmente proyectado ${ }^{(57)}$. Gran parte de las renegociaciones se debieron a la insuficiencia de estudios de ingeniería y geológicos, así como a la presencia de fallas geológicas escondidas (Ruiz 2018, 17-19)(58). La ausencia de estudios técnicos fue posible debido a la exclusión de IIRSA Sur del Sistema Nacional de Inversión Pública (SNIP). Hoy se sabe que esta decisión fue consecuencia de actos de corrupción que involucraron hasta al Presidente de la República de ese momento.

No obstante, la adjudicación de IIRSA Sur fue considerada, en su época, como un éxito político. El proyecto era apoyado por la población y las autoridades de las principales ciudades del sur, por instituciones financieras, así como por el gobierno brasileño. Estos hechos también influyeron para que las entidades públicas optasen por darle sostenibilidad, pese a los sobrecostos generados por las múltiples adendas que debieron celebrarse casi inmediatamente después de su suscripción ${ }^{(59)}$ (Ruiz 2018, 17-23). Incluso la academia y las agencias multilaterales consideraron, inicialmente, que los beneficios sociales de dicho proyecto eran superiores a sus $\operatorname{costos}^{(60)}$. No obstante, luego de los sobrecostos ocasionados por sus múltiples adendas, se ha constatado que el proyecto no ha sido rentable (Bonifaz 2017).

\subsection{Los costos de una renegociación excesiva}

Como acertadamente acota Ruiz $(2015,19)$, al optar por adjudicar proyectos APP que carecían de estudios y un nivel de compleción adecuado, el Estado peruano "descontó" excesivamente el costo futuro que acarrearían las renegociaciones. En otras palabras, no supo valorar, en toda su magnitud, las consecuencias de su comportamiento oportunista:

“(...) el elevado número de renegociaciones en el Perú parece reflejar un equilibrio

(55) Otras entidades, como los organismos reguladores, tienen incentivos distintos, pues su objetivo principal es el cumplimiento de las obligaciones de los concesionarios para garantizar la calidad y eficiencia del servicio brindado al usuario. Para lograrlo, es necesario asegurar la sostenibilidad de los proyectos a largo plazo y, en ese sentido, el regulador prefiere tener cláusulas que sean lo más completas posibles, de manera que se asegure la viabilidad técnica, legal y financiera del proyecto. Por eso, para Ruiz (2015, 21) es necesario fortalecer la participación de los reguladores tanto en la etapa de formulación como en los supuestos de renegociación del contrato.

(56) El Comité de Operaciones del Sistema Interconectado Nacional (COES) recomendó no ejecutar la obra debido a problemas técnicos y medio ambientales. Véase https://elcomercio.pe/economia/dia-1/linea-transmision-moyobamba-iquitos-ejecutarse-noticia-462678

(57) De acuerdo a la Comisión Lava Jato, el sobrecosto del Tramo 2 de la Interoceánica del Sur es de 391 millones de dólares y el del Tramo 3 es 291 millones de dólares (citado en: IDL-Reporteros. 2016. Los sobrecostos de Odebrecht en el Perú. Ver: https://idlreporteros.pe/los-sobrecostos-de-odebrecht-en-peru/). Asimismo, la Contraloría General de la República concluyó que en el Tramo 4 hay sobrecostos por más de 37 millones de dólares. Véase https://elcomercio.pe/politica/hallan-sobrecostos-interoceanica-surus-37-millones-noticia-533222.

(58) Ruiz comenta el Informe elaborado por el congresista Juan Pari en el año 2016, en el cual está incluida la declaración de Verónica Zavala, Ministra de Transportes y Comunicaciones durante el gobierno de Alan García, quien habría señalado lo siguiente: "En mi opinión el origen del problema está en la insuficiencia de los estudios geológicos y de ingeniería que se realizaron, insuficiencia que generó una subestimación de los costos de la obra. En lugar de realizarse los estudios de campo se hicieron estudios menos profundos amparados en la exoneración del SNIP que se autorizó con el Decreto Supremo 022-2005-EF. De haberse tenido los estudios geológicos y de ingeniería se habría podido contar con un contrato a suma alzada en lugar de fijarse en término de precios unitarios. Así, cuando el concesionario realizó la ingeniería de detalle, se encontraron características geológicas del suelo que elevaron el volumen de metrados de obras y por consiguiente su valor total" (página 34 del Informe Pari).

(59) Para Ruiz (2018, 17-19), esto fue decisivo para lograr la aprobación de adendas que significaron altos sobrecostos, teniendo en cuenta que pasaron por el regulador, del Ministerio de Economía y Finanzas e, incluso, Contraloría.

(60) Al respecto, véase Ruiz $(2018,18)$, citando a Bonifaz, José Luis y Urrunaga, Roberto. 2008. Beneficios económicos de la carretera Interoceánica. Lima: Centro de Investigación de la Universidad del Pacífico y Corporación Andina de Fomento. 2013. Carretera Interocéanica Sur del Perú. CAF: Bogotá. 
imperfecto entre los objetivos de minimizar la renegociación costosa ex post (y completar contratos) con los intereses del gobierno de cumplir sus metas de promoción de la inversión. A pesar del hecho que completar los contratos de concesión puede ser costoso en tiempo y recursos, los resultados reportados parecen reflejar que los gobiernos de turno han descontado excesivamente los costos futuros de las renegociaciones"(61).

Efectivamente, muchos son los costos de un modelo que privilegia el rédito político a la reducción de la frecuencia en la renegociación de los contratos APP. Entre los más graves, está el impacto en la reputación y credibilidad del gobierno, pues evidencia que el contrato adjudicado no es realmente vinculante. Esto no es una buena señal para la inversión, ya que promueve la proliferación de ofertas temerarias y comportamientos oportunistas, confiados en obtener mejores condiciones mediante la renegociación, escenario que ahuyenta a los inversionistas serios:

"Una revisión de una muestra de casi 60 APP adjudicadas en el periodo 2000-2015 reveló que si bien cerca de 80 empresas de 20 países habían sido adjudicatarias de proyectos -con una mayor diversidad de concesionarios en los últimos años de la muestra-, la participación de empresas de países con calificación crediticia de alto grado de inversión (A- o superior) era prácticamente nula. Empresas líderes en el mundo en operación de APP, provenientes de países reconocidos como aquellos con los sistemas de APP más desarrollados (Reino Unido, Australia), no venían al Perú. Las razones específicas son diversas, y varias de ellas ya han sido mencionadas: marco normativo disperso y potencialmente confuso, procesos dispares, ventanas cortas de promoción y convocatoria, limitado portafolio de proyectos de escala, entre otras. Adicionalmente, en múltiples proyectos se encontraron diferencias muy significativas entre los valores referenciales para los compromisos de inversión y de operación y mantenimiento, frente a los montos ofertados por los postores ganadores. Las ofertas ganadoras eran sustancialmente menores. Esto puede deberse a distintas razones, incluyendo valores referenciales imprecisos debido a estudios no suficientemente detallados, pero también podría explicarse por ofertas agresivas o temerarias orientadas a ganar los concursos y solicitar renegociaciones oportunistas posteriores, socavando los fundamentos de un proceso competitivo y disuadiendo la participación de nuevos inversionistas" (Benavente y Segura 2017, 47 y 48).

En segundo lugar, la frecuente renegociación deslegitima el modelo de APP, afectando la inversión y el financiamiento de proyectos. Genera, también, desconfianza en la población respecto a dicho modelo (particularmente luego del escándalo "Lava Jato"). En palabras de Ruiz (2015, 4), "un régimen permisivo con respecto a las renegociaciones ex post puede incrementar la percepción de riesgo de los inversionistas en el largo plazo, socavando y debilitando el sistema de concesiones como un todo"(62).

En tercer lugar, el retraso en el que incurre el Estado en cumplir obligaciones tan esenciales como la entrega de terrenos puede poner en riesgo la continuidad del proyecto mismo, además de incrementar sus costos, reduciendo los fondos que podrían destinarse a otros proyectos de interés público. Crea, asimismo, descontento social por el retraso en la ejecución de infraestructura considerada esencial y políticamente sensible, eliminando los beneficios que se derivarían de suscribir tempranamente el contrato con el afán de adelantar su ejecución. Por ejemplo, la celebración de un contrato que carece de cláusulas de bancabilidad adecuadas ocasiona sobrecostos al impedir obtener oportunamente el financiamiento necesario para iniciar la obra en los plazos previstos. Esta situación obliga a compensar al concesionario con garantías del gobierno y/o la extensión del plazo de la concesión (EY 2016, 59).

En cuarto lugar, las frecuentes renegociaciones neutralizan los beneficios que se derivan de un proceso competitivo de promoción de la inversión, en el que los operadores hacen su mejor oferta, incentivados por la competencia y el objetivo de ganar. En el proceso de renegociación ya no hay competencia; concedente y concesionario llevan a cabo una negociación

(61) Traducción libre de: “(...) the high number of renegotiations in Peru may reflect an imperfect balance between the objectives of minimizing costly ex post bargaining (and completing contracts) with the Government interests of accomplishing their investment promotion goals. Despite the fact that completing concession contracts may be costly in time and resources, the results reported may reflect that Peruvian Governments have discounted excessively the future costs of renegotiations."

(62) Traducción libre de: "(...) a lax or permissive regime with respect to ex post renegotiations may increase the perceived risk for investors in the long term, undermining and delegitimizing the concession system as a whole." 
bilateral sobre aspectos en los que, usualmente, existe asimetría en la información. A la pérdida de las ventajas derivadas de un proceso competitivo, se suma que en el caso de proyectos adjudicados por CPI, es el privado quien elabora el proyecto, así como los estudios de detalle sobre los que realizará su ejecución, lo cual acentúa la asimetría de la información entre el privado y el Estado durante una eventual renegociación contractual.

Sobre la pérdida de beneficios de una licitación competitiva, explica Guasch $(2005,38)$ :

“La renegociación, y la renegociación oportunista en particular, puede menoscabar o eliminar los beneficios esperados de una licitación competitiva. Si la subasta está diseñada correctamente y ofrece suficientes incentivos, el proceso de licitación competitiva, con miras a la adjudicación del derecho de operar una concesión durante una cantidad determinada de años, debería encontrar (seleccionar) al operador más eficiente. Si los ofertantes perciben que la renegociación es factible y probable, entonces sus incentivos así como sus ofertas se verán afectados. De esta manera, es probable que, mediante el proceso, no se seleccione al operador más eficiente sino al más habilidoso en cuestiones de renegociación. Las renegociaciones solo deben desarrollarse cuando están justificadas por las contingencias."

En quinto lugar, tratándose de proyectos cofinanciados, las renegociaciones originadas en estudios técnicos deficientes llevan con frecuencia a incrementos del presupuesto. Como Céspedes y Paz $(2018,256)$ han identificado:

"en un escenario en el que los estudios brindados por el concedente son deficientes, se genera un espacio propicio para que el concesionario plantee soluciones técnicas que podrían no ser las más beneficiosas para el concedente, provocando incluso un mayor compromiso o endeudamiento fiscal."

Como ejemplo, puede mencionarse el caso del Primer Grupo de Aeropuertos Regionales, que requirieron adendas que incrementaron el cofinanciamiento, a pesar de que este fue, precisamente, el factor de competencia para su adjudicación (Contraloría 2015, 275-276).

En sexto lugar están los costos procesales que deben asumir las partes, cuando para resolver las diferencias originadas en un contrato de concesión ambiguo, incompleto y pobremente redactado deben recurrir a un tribunal arbitral. Para las controversias de mayor envergadura, este es el Centro Internacional de Arreglo de Diferencias relativas a Inversiones
(CIADI) ante el que se han interpuesto 20 demandas contra el Estado peruano ${ }^{(63)}$. Los costos de estos arbitrajes son millonarios y pagados con recursos públicos.

Lamentablemente, estos costos no están a la vista cuando el gobierno de turno debe optar entre adjudicar prematuramente un proyecto o esperar a que cuente con estudios suficientes, una asignación de riesgos eficiente y contratos razonablemente completos. A lo anterior se agrega la tentación de adjudicarse un rédito político, que pesa más que los problemas futuros que ocasionan los proyectos de APP deficientemente estructurados.

\section{Referencias bibliográficas}

Alberti, Juan y Pereyra, Andrés. 2018. Carretera Interoceánica IIRSA Sur de Perú. Un megaproyecto con preinversión express. Banco Interamericano de Desarrollo.

Alonso, Iván. 2009. La asignación de riesgos en las concesiones de carreteras cofinanciadas. Revista de Regulación en Infraestructura de Transporte 4, año 2.

Ariño Ortiz, Gaspar. 2004. Principios de Derecho Público Económico. Lima: ARA Editores.

Barrionuevo, Ana y Watanabe, Angie. 2015. Demora en la entrega de predios necesarios para la ejecución de proyectos viales concesionados. Tesis para optar por el grado académico de Magíster en Regulación de Servicios Públicos y Gestión de Infraestructura, Universidad del Pacífico.

Benavente, Patricia y Segura, Alonso. 2017. Luces y sombras del modelo de APP en la experiencia peruana. En Las Alianzas Público-Privadas (APP) en el Perú: beneficios y riesgos, coordinadora Patricia Benavente, José Escaffi, Alonso Segura y José Távara, 20-61. Lima: Pontificia Universidad Católica del Perú.

Bonifaz, José Luis. 2017. La Interoceánica y nuestros estudios. El Comercio, 24 de febrero de 2017.

(63) Han concluido a la fecha 14 casos. Información obtenida del portal web de CIADI: https://icsid.worldbank.org/sp/Pages/cases/ AdvancedSearch.aspx\# 
Bonifaz, José Luis; Urrunaga, Roberto; Aguirre, Julio; y Urquizo, César. 2015. Un plan para salir de la pobreza: Plan Nacional de Infraestructura 2016-2025. Lima: Asociación para el Fomento de la Infraestructura Nacional - AFIN.

Cassagne, Juan Carlos. 1999. El Contrato Administrativo. Buenos Aires: Abeledo-Perrot.

2014. Los marcos regulatorios de los Servicios Públicos y la inserción de la técnica contractual. La Ley 174 , año LVIII: 966.

Céspedes, Josselyne y Paz, Miguel Ángel. 2018. Alteración en la asignación de riesgos en las concesiones cofinanciadas de infraestructura de transporte de uso público mediante modificaciones contractuales. Tesis para optar por el grado académico de Magíster en Regulación de los Servicios Públicos, Pontificia Universidad Católica del Perú.

Chamorro Vilca, Mery. 2013. Apuntes respecto a las modificaciones de los contratos de concesión en el sector energía otorgados por el TUO de Concesiones. Revista Peruana de Energía 2: 149-171.

Cienfuegos, Mijail. 2019. Las renegociaciones contractuales de las Asociaciones Público-Privadas en el Perú: Problemática actual y aportes críticos. Tesis para el título profesional de abogado., Universidad Nacional Mayor de San Marcos.

Contraloría General de la República. 2015. Causas y efectos de las renegociaciones contractuales de las Asociaciones Público-Privadas en el Perú. Lima.

Defensoría del Pueblo. 2018. Reporte Mensual de Conflictos Sociales No. 178. https://www.defensoria.gob.pe/wp-content/ uploads/2019/01/Conflictos-Sociales-N\%C2\%B0-178Diciembre-2018.pdf (consultada el 30 de diciembre 2018).

EY. 2016. Agilizando la ruta del crecimiento: II Parte del Plan Nacional de Infraestructura 2016-2025. Lima: AFIN.

Guasch, José Luis. 2005. Concesiones en infraestructura. Cómo hacerlo bien. Banco Mundial.

IDL-Reporteros. 2016. Los sobrecostos de Odebrecht en el Perú.

https://idl-reporteros.pe/los-sobrecostos-de-odebrecht-enperu/.

Mertehikian, Eduardo. 1996. La iniciativa privada en la concesión administrativa (Breves reflexiones sobre su aplicación por los municipios bonaerenses). Revista de Administración Pública 218 (noviembre).

Mestre Delgado, Juan Francisco. 1992. La Extinción de la Concesión de Servicio Público. Madrid: La Ley.

Montesinos, Jorge y Saavedra, Eduardo. 2012. Algunos alcances en torno a la institucionalidad y renegociación de concesiones en la infraestructura de uso público en
Perú. http://fen.uahurtado.cl/wp-content/ uploads/2010/07/I-277.pdf

Morón Urbina, Juan Carlos y Aguilera Becerril, Zita. 2014. La modificación convencional de los contratos administrativos: necesidad, límites y regulación. En Tendencias Actuales de Contratación Pública, dir. Eloy EspinosaSaldaña. Lima: Gaceta Jurídica.

Pérez Hualde, Alejandro. 2009. Renegociación de contratos de gestión de servicios públicos. Revista de Derecho Administrativo 7: 275284.

Prolnversión. Reporte de proyectos - Todas las modalidades a diciembre 2017. https://www.proinversion.gob.pe/ RepositorioAPS/0/0/JER/ESTADISTICAS GRAL/diciembre_2017/3_2_\%20 Reporte $\% 20$ de $\% 20$ Proyectos $\% 20-\% 20$ Todas $\% 201$ as $\% 20$ modalidades $\% 20 a \% 20$ DICIEMBRE\%202017.xIs

Reyes, José Carlos. 2018. Linea 2 del Metro: Segunda adenda al contrato se firmará a más tardar en agosto. Gestión.pe, 4 de julio de 2018. [https://gestion.pe/economia/linea2-metro-segunda-adenda-contrato-firmaratardar-agosto-237481].

Ronceros, Miguel Ángel. 2006. Concesiones Cofinanciadas y PPP. THEMIS 52: 231-238.

Ruiz, Gonzalo. 2015. Incompleteness and renegotiation of concession contracts: An Empirical Evaluation. Journal of Applied Sciences 31, volumen X: 104-127.

2018. Opportunism and Third-Party Influence on Long-Term Public Contracts. Documento de Trabajo No. 456. Lima: Pontificia Universidad Católica del Perú. http:// files.pucp.edu.pe/departamento/economia/ DDD456.pdf

Shimabukuro Tokashiki, Néstor. 2013. Algunos cuestionamientos al régimen de promoción de la inversión privada en los proyectos de inversión privada provenientes de iniciativas privadas de competencia del Gobierno Nacional. Revista de Derecho Administrativo 13: 103-122.

Suto, Fénix; Azaña, Roxana; Chamorro, Mery; León, Lorena; Menchola, Muriel. 2013. Renegociación contratos de concesión en infraestructura de transporte: Diagnóstico, 
Análisis y Propuestas de Mejora. Lima: Universidad ESAN.

Távara, José. 2017. Las Asociaciones Público-Privadas en el contexto actual. En Las Alianzas Público-Privadas (APP) en el Perú: beneficios y riesgos, coordinadora Patricia Benavente, José Escaffi, Alonso Segura y José Távara, 62-103. Lima: Pontificia Universidad Católica del Perú.
Tawil, Guido. 2016. Los principios en el contrato de concesión de servicios públicos. En El Control de la Actividad Estatal II. Procesos Especiales, Responsabilidad y Otros Supuestos, dir. Enrique M. Alonso Regueira, 837849. Buenos Aires: Asociación de Docentes de la Facultad de Derecho y Ciencias Sociales de la Universidad de Buenos Aires.

Zúñiga Aleman, Laura. 2012. Project finance de proyectos de infraestructura. THEMIS 62: 255-276. 